\title{
Understanding FinTech start-ups - a taxonomy of consumer-oriented service offerings
}

\author{
Henner Gimpel $^{1} \cdot$ Daniel Rau $^{1}$ (D) $\cdot$ Maximilian Röglinger $^{1}$
}

Received: 17 November 2016 / Accepted: 18 October 2017 / Published online: 8 November 2017

(C) The Author(s) 2017. This article is an open access publication

\begin{abstract}
The financial sector is facing radical transformation. Leveraging digital technologies to offer innovative services, FinTech start-ups are emerging in domains such as asset management, lending, or insurance. Despite increasing investments, the FinTech phenomenon is low on theoretical insights. So far, the offerings of FinTech start-ups have been predominantly investigated from a functional perspective. As a functional perspective does not suffice to fully understand the offerings of FinTech start-ups, we propose a taxonomy of nonfunctional characteristics. Thereby, we restrict our analysis to consumer-oriented FinTech start-ups. Our taxonomy includes 15 dimensions structured along the perspectives interaction, data, and monetization. We demonstrate the applicability of our taxonomy by classifying the offerings of 227 FinTech start-ups and by identifying archetypes via a cluster analysis. Our taxonomy contributes to the descriptive knowledge on FinTech start-ups, enabling researchers and practitioners to analyze the service offerings of FinTech start-up in a structured manner.
\end{abstract}

JEL classification $\mathrm{M} 13 \cdot \mathrm{N} 2 \cdot \mathrm{N} 7 \cdot \mathrm{O} 3$

Responsible Editor: Rainer Alt

Daniel Rau

daniel.rau@fim-rc.de

Henner Gimpel

henner.gimpel@fim-rc.de

Maximilian Röglinger

maximilian.roeglinger@fim-rc.de

1 FIM Research Center, University of Augsburg, 86135 Augsburg, Germany
Keywords Financial services · Financial technology FinTech $\cdot$ Business model $\cdot$ Services $\cdot$ Taxonomy

\section{Introduction}

The financial sector is facing radical transformation. FinTech start-ups, an abbreviation for financial technology start-ups, revolutionize how customers experience financial services (Mackenzie 2015). Leveraging digital technologies, FinTech start-ups offer innovative financial services and boost developments in domains such as payment, wealth management, or trading (Chuen and Teo 2015; Kim et al. 2016). For instance, TransferWise offers international money transfer online and at low cost. Wealthfront, another FinTech start-up, unleashes the potential of private wealth management to low-income individuals.

Considering the previous development in electronic markets, the FinTech phenomenon is a logical evolutionary step. It was the Internet that enabled e-commerce in the 1990s, followed by dynamic Web services, standardization, and the integration of e-business technologies in enterprise applications. In recent years, the mobile channel, cloud-based services, and big data analytics drove the transformational shift to consumerization, i.e., the offering of user-centered life solutions in areas such as health, mobility, or finance (Alt and Zimmermann 2014). In today's financial services sector, FinTech start-ups offer consumer-oriented banking, insurance, and other financial services (Alt and Puschmann 2012). They are the key innovation driver with experts predicting a very promising future. In 2014, global investments in FinTech tripled to more than USD 12 billion (Dietz et al. 2015), and in 2015, investments increased even further (Mead et al. 2016). Offering innovative financial services as asset-light and compliance-easy organizations, FinTech start-ups evolve into 
challenging competitors and strong allies of traditional financial institutions (Chuen and Teo 2015). By 2020, FinTech start-ups are estimated to handle over $20 \%$ of the financial service business (Kashyap et al. 2016). Accordingly, traditional financial institutions massively invest in the digitalization of their services. For instance, Germany's largest bank announced to invest EUR 1 billion in digitalization until 2020 (Deutsche Bank 2015), and the second largest Spanish bank has invested an annual average of around EUR 800 million since 2011 (BBVA 2015). Traditional institutions increasingly aim to benefit from alliances with FinTech start-ups, setting up venture capital funds beyond USD 100 million (Dany et al. 2016). Due to these high investments and the central role of FinTech start-ups in the financial sector, it is worthwhile to strive for an in-depth understanding of the service offerings of FinTech start-ups.

Despite the rising importance of FinTech start-ups, the FinTech phenomenon is low on theoretical insights. Academic insights are scarce and most related publications are commercial reports (Zavolokina et al. 2016). Today, we do not fully understand how the service offerings of FinTech start-ups can be characterized, what they have in common, and how they differ. FinTech services are usually classified from a functional perspective including domains such as account management, savings, or crowdfunding (Dany et al. 2016; Dietz et al. 2015; Gulamhuseinwala et al. 2015). While the functional perspective helps group FinTech start-ups with respect to what they do for customers, it does not suffice to fully understand how FinTech start-ups configure their offerings. What is missing is a nonfunctional view on the service offerings of FinTech start-ups that abstracts from FinTech start-ups' specific function for consumers (O'Sullivan et al. 2002). A non-functional classification of FinTech services will help understand both the FinTech phenomenon and the role of FinTech start-ups in the financial sector.

Especially for consumer-oriented FinTech start-ups, we expect a large increase of knowledge. In particular, we are interested in the interaction between start-ups and individual consumers, as consumerization and the provision of customercentric life solutions are major trends in the electronic markets field (Alt and Puschmann 2012). Further, more information is publicly available about consumer-oriented FinTech start-ups. Therefore, we focus on consumer-oriented FinTech start-ups, excluding start-ups that primarily address businesses, focus on financial services providers' internal processes, or facilitate exchange between two or more financial service providers without consumer involvement. We focus on FinTech startups, as they represent the spearhead of innovation in the financial sector, while traditional institutions struggle to cope with legacy systems and structures. Further, FinTech start-ups are less understood and, thus, call for more intense research compared with FinTech-based services of traditional financial institutions. As existing classification schemes for FinTech and services do not cover the non-functional perspective of
FinTech start-ups, we investigate the following research question: What are the non-functional characteristics of consumer-oriented FinTech start-up service offerings?

To answer our research question, we propose a taxonomy that helps classify FinTech start-up service offerings. To do so, we iterate the taxonomy development process of Nickerson et al. (2013). Structured along the perspectives interaction, data, and monetization, we derive 15 dimensions and related characteristics from the literature and exemplary FinTech start-ups. We validated our taxonomy by classifying the offerings of 227 FinTech start-ups, identifying archetypes per perspective using hierarchical clustering, and examining relationships among these archetypes.

Our taxonomy addresses two user groups: researchers, who analyze FinTech start-ups and develop theories in this field, and practitioners, who design or evaluate FinTech start-ups and their offerings. Both groups can use our taxonomy for gaining a deeper understanding of the FinTech phenomenon, identifying core dimensions of FinTech start-up service offerings, defining typical service characteristics based on our taxonomy, analyzing the market of consumer-oriented FinTech start-ups, and identifying comparable non-competitive services.

The remainder of this paper is structured as follows. First, we provide background information about FinTech start-ups and existing service taxonomies. Second, we outline our research method. Third, we present our taxonomy of FinTech start-up service offerings. Fourth, we apply our taxonomy to 227 real-life examples and identify archetypes via cluster analysis. Fifth, we discuss the implications and limitations of our work. We conclude with a brief summary and outline of future research opportunities.

\section{Domain background}

\section{FinTech and FinTech start-ups}

FinTech is the abbreviation of "financial technology," which is a blend of "financial services" and "information technology" (Oxford English Dictionary n.d.). The term FinTech was first used in the early 1990s in the name of a project by Citigroup predecessor to foster technological collaboration (Hochstein 2015). Since 2014, it has gained attention in contexts such as innovative business models (Google 2016). Despite low theoretical insights into the FinTech phenomenon, we draw from its few mentions in academic literature and perspectives from commercial publications to derive a working definition, verified by observations made during our study.

Academic and commercial literature characterizes FinTech differently. Generally, FinTech is referred to as innovative and personalized financial services and products (Allen and Overy LLP 2015; Chuen and Teo 2015; Dany et al. 2016; Dapp 2014, 
2015; Dietz et al. 2015; Gulamhuseinwala et al. 2015; Kim et al. 2016). Whereas Drummer et al. (2016) as well as Gulamhuseinwala et al. (2015) relate FinTech to business models, Kim et al. (2016) consider it an entire sector. Zavolokina et al. (2016) summarize that either new services, products, processes, or business models emerge with FinTech. Dany et al. (2016) highlight customer centricity as a constitutive characteristic of FinTech services (Chuen and Teo 2015; Gulamhuseinwala et al. 2015). All sources agree that FinTech leverages digital technologies such as the Internet, Internet of Things, mobile computing, and social media (Allen and Overy LLP 2015; Chuen and Teo 2015; Dany et al. 2016; Dapp 2014, 2015; Dietz et al. 2015; Drummer et al. 2016; Gulamhuseinwala et al. 2015; Kim et al. 2016; Zavolokina et al. 2016). Many sources also mention the use of data analytics and artificial intelligence (Allen and Overy LLP 2015; Dany et al. 2016; Dapp 2014, 2015). By leveraging emerging digital technologies, FinTech enables, innovates, and disrupts the financial services market (Allen and Overy LLP 2015; Gulamhuseinwala et al. 2015; Kim et al. 2016; Zavolokina et al. 2016). Zavolokina et al. (2016) argue that, besides technology, FinTech is a development within start-ups and established companies nurtured by substantial monetary investments. Distilling the essence of the definitions above, we define FinTech and FinTech start-ups as follows:

FinTech characterizes the usage of digital technologies such as the Internet, mobile computing, and data analytics to enable, innovate, or disrupt financial services.

FinTech start-ups are newly established businesses that offer financial services based on FinTech.

Today, FinTech start-ups cover many consumer-facing elements of the financial value chain. Table 1 overviews major groups of financial services and exemplary FinTech start-ups. Apparently, most FinTech start-ups address one particular financial service such as money transfer or trading.

From an industry perspective, FinTech start-ups are typically non-financial businesses such as technology-driven companies and online businesses (Dapp 2014, 2015; Gulamhuseinwala et al. 2015; Kim et al. 2016). Although some start-ups hold a full banking license (e.g., N26), most do not. To offer services that require a full banking license or to leverage the regulatory and risk management experience of traditional financial institutions (The Economist Intelligence Unit 2015), some FinTech start-ups, such as auxmoney, collaborate with traditional financial institutions (Dany et al. 2016; Dapp 2015; Gulamhuseinwala et al. 2015) or newly established "white label" banks such as solarisBank.

With multiple venture-capital investments in recent years, the FinTech start-up development rapidly accelerated globally, unfolding its full dynamics with tremendous growth (Dietz et al. 2015; Gulamhuseinwala et al. 2015). In 2014, over three- quarters of the global FinTech investment was spent in the US, $10 \%-15 \%$ in Europe, and 5\%-10\% in Asia (Dietz et al. 2015). Because of low bureaucratic boundaries, deep understanding of customer needs, and dynamic teams with high technical skills, FinTech start-ups stand out with short development cycles and time-to-market. Though they follow a customer-centric strategy, long-term success rates are not yet available and earnings remain uncertain. However, they are attractive to traditional financial institutions, which already invested in FinTech partnerships, acquisitions, and internal incubators to expand their service portfolios to reach new customer segments and enrich customer experience (Dany et al. 2016).

\section{Service taxonomies}

The term "taxonomy" is often used interchangeably with "framework" or "typology". Taxonomies help structure and organize knowledge, grouping objects from a distinct domain based on common characteristics and explaining the relationships among these characteristics (Cook et al. 1999; Nickerson et al. 2013). Taxonomies are needed if little knowledge is available (Gregor 2006). As FinTech is an emerging phenomenon, there is little guidance on the analysis of existing and the design of new FinTech start-up service offerings.

In the literature, there are taxonomies that differentiate financial services from other services (Guile and Quinn 1988), structure the role of technology in service provision (Fitzsimmons and Fitzsimmons 2008; Froehle and Roth 2004), and discuss non-functional service properties (O'Sullivan et al. 2002). Though being insufficient to fully understand the service offerings of FinTech start-ups, these taxonomies are a good starting and reference point. Below, we introduce service taxonomies relevant for our purposes (Fitzsimmons and Fitzsimmons 2008; Leimeister 2012; Meffert and Bruhn 2009; Park et al. 2012.

Guile and Quinn 1988 classify services based on their role in an economy. Such roles are financial, government, or infrastructure services. Accordingly, services are an integral rather than a peripheral part of the economy (Fitzsimmons and Fitzsimmons 2008). Froehle and Roth (2004) focus on the role of technology in service encounters, presenting five archetypes of technology-related customer contact. In the technology-free mode, the service encounter involves interactions between customers and human service providers. In the technology-assisted mode, only the service representative uses technology. The technology-facilitated mode allows customers and service representatives to use the same technology. There is no face-to-face contact in the technology-mediated mode via communication technology and the technologygenerated mode where human service providers are entirely replaced by technology. Based on the triad of customers, contact personnel, and service organization, Fitzsimmons and Fitzsimmons (2008) differentiate services by the party that 
Table 1 Major functional domains of financial services and exemplary FinTech start-ups

\begin{tabular}{lll}
\hline Functional domain & Justificatory references & FinTech start-up examples \\
\hline Account management & Dietz et al. (2015), Drummer et al. (2016) & Centralway Numbrs, N26 \\
Asset management, investments, and savings & $\begin{array}{c}\text { Dany et al. (2016), Dietz et al. (2015), Drummer et al. (2016), } \\
\text { Gulamhuseinwala et al. (2015) }\end{array}$ & Digit, Wealthfront \\
Crowdfunding / crowdinvesting & Chuen and Teo (2015), Dany et al. (2016) & Bergfürst, Funding Circle \\
Cryptocurrencies & Chuen and Teo (2015), Dany et al. (2016) & bitcoin.de, Xapo \\
Financial planning & Dany et al. (2016) & Betterment, LearnVest \\
Insurance & Dany et al. (2016), Gulamhuseinwala et al. (2015) & Coverfox, Friendsurance \\
Lending and financing & Dany et al. (2016), Dietz et al. (2015), Drummer et al. (2016), & Affirm, Avant \\
Payment and money transfer & Gulamhuseinwala et al. (2015) & goHenry, TransferWise \\
Peer-to-peer lending & Chuen and Teo (2015), Dany et al. (2016), Dietz et al. (2015), \\
Trading & Drummer et al. (2016), Gulamhuseinwala et al. (2015) & auxmoney, Lending Club \\
Others & Chuen and Teo (2015) & eToro, Robinhood \\
\hline & Dany et al. (2016) & BankingCheck, CreditKarma
\end{tabular}

dominates the service encounter. In service-organizationdominated encounters, service provision is highly standardized, while personalization via contact personnel is limited or fully restricted. In contact-personnel-dominated encounters, customers have little control as they are in a subordinate position. In customer-dominated encounters, either a high degree of personalization and customization or full control over self-service fosters customer sovereignty. Finally, O'Sullivan et al. (2002) describe non-functional properties as characterizing services independent from their application domain or function to the customer. O'Sullivan et al. (2002) suggest distinguishing services by temporal and spatial availability, channels used for customer-company interaction, charging styles used for monetization, settlement as mutual obligations of the service provider and requester, payment obligations included in settlement contracts, service quality as difference between expected and actual service provision, security and trust as foundational properties, and ownership and rights associated with service delivery.

In line with the service taxonomy of Guile and Quinn (1988), FinTech start-up service offerings can be classified as financial services. However, this taxonomy does not enable further differentiating financial services. Following the taxonomy of Froehle and Roth (2004), FinTech start-up service offerings can feature all modes of technology in the service encounter except for the technology-free and -assisted modes. Due to their use of digital technologies, most FinTech service offerings are technology-mediated or -generated. Though not fully explaining the differences between FinTech start-up service offerings, the ideas of Froehle and Roth (2004) can be incorporated in the development of our taxonomy, shedding light on the role of technology in the interaction between FinTech start-up and consumer. In line with the main idea of FinTech start-ups, most service offerings can be classified as customer-dominated encounters of Fitzsimmons and
Fitzsimmons' (2008) service taxonomy. The service taxonomy of O'Sullivan et al. (2002) suggests dimensions that can be incorporated in the development of our FinTech taxonomy. Basically, FinTech start-up service offerings are accessible without temporal or spatial restrictions. Due to regulatory or economic reasons, there may be national boundaries of service availability. Further, FinTech start-ups use digital channels and vary in their charging style, settlement, payment obligations, service quality, security and trust, and ownership and rights. The service taxonomy of O'Sullivan et al. (2002) as a whole is not sufficient to answer our research question as important dimensions such as personalization or use of data are missing. As these taxonomies do not fully explain FinTech start-up service offerings from a non-functional perspective, we designed a new taxonomy that includes relevant dimensions from extant taxonomies.

\section{Research method}

In this study, we combine qualitative and quantitative research (Bryman 2006). In the qualitative part, we develop a taxonomy of FinTech start-up service offerings. In the quantitative part, we apply our taxonomy to classify real-life examples and group them using cluster analysis. This section focuses on the taxonomy development process. Details on the cluster analysis can be found in the application section.

Figure 1 shows the iterative taxonomy development process as per Nickerson et al. (2013) that consists of seven steps. After the definition of a meta-characteristic, which serves as foundation for all other characteristics of the taxonomy, objective and subjective ending conditions are defined. For each iteration of steps 3 to 7, the empirical-to-conceptual (inductive; in case of sufficient real-world data) or conceptual-to-empirical approach (deductive; leveraging knowledge of the authors and from the 
Fig. 1 Taxonomy development process in information systems

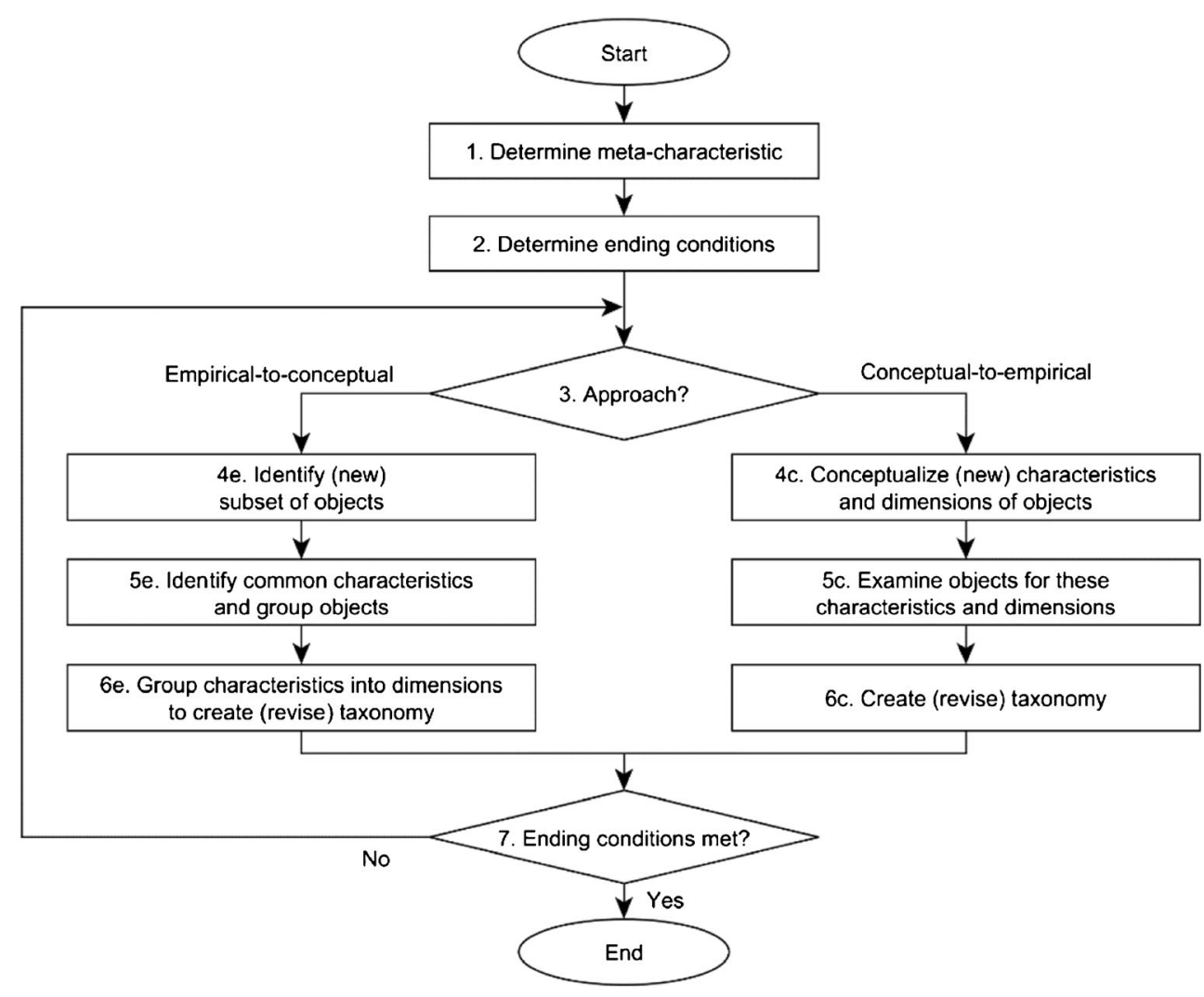

literature) can be chosen. In an empirical-to-conceptual iteration, a sample of real-world objects is drawn from which common characteristics are derived and grouped into dimensions. In conceptual-to-empirical iterations, characteristics and dimensions are derived based on the authors' knowledge and from the literature related to the meta-characteristic. These conceptually derived characteristics and dimensions are then verified against real-world objects. The taxonomy is revised after each iteration. The taxonomy development process iterates until the ending conditions are met.

We iterated the taxonomy development process as follows: As for the meta-characteristic in step (1), we chose "non-functional characteristics of consumer-oriented FinTech start-up service offerings in the perspectives interaction, data, and monetization". Compared with traditional financial institutions, FinTech start-ups do not have completely different service offerings. However, differences can be observed in three areas. Due to the consumerization trend in the electronic markets field (Alt and Zimmermann 2014) and in line with service-dominant logic that describes value co-creation as essential for services (Vargo and Lusch 2004), it is important to understand the interaction between FinTech start-ups and customers (Setia et al. 2013). Further, data processing has always been at the core of financial services. Nowadays, technology not only changes the interaction between service providers and customers, but also expands the role and possibilities of data analytics (Baesens et al. 2016). Finally, new monetization models emerge as users of financial services need not necessarily pay for services with money
(Baden-Fuller and Haefliger 2013; Clemons 2009; Skilton 2015). This shift can also be observed in other industries. For example, Facebook offers its users a free social network, but earns money by allowing companies to conduct target marketing based on user data. During the taxonomy development process, we checked if a major perspective is missing in our taxonomy. However, all identified non-functional characteristics and dimensions could be matched to one of the three perspectives just outlined. Thus, interaction, data, and monetization are essential when systematizing the service offerings of consumer-oriented FinTech start-ups. Our taxonomy does not claim to cover the entire business model of FinTech start-ups, as this would require investigating other perspectives such as ownership structure, funding, and employee structure. Instead, our taxonomy focuses on non-functional properties of such service offerings.

As for the ending conditions in step (2), we chose "at least one object is classified under every characteristic of every dimension," "no new dimensions or characteristics were added in the last iteration," and "no dimensions or characteristics were merged or split in the last iteration" from the list of objective ending conditions proposed by Nickerson et al. (2013). If the taxonomy is considered concise, robust, comprehensive, extendible, and explanatory, we assumed subjective ending conditions to be met (Nickerson et al. 2013).

In four iterations of steps (3) to (7), we used the conceptual-toempirical (iteration 1) and empirical-to-conceptual (iterations 2 to 4) approach to derive a diverse set of characteristics and dimensions. In iteration 1, we examined the literature on existing service 
taxonomies, FinTech, customer-company interaction, data processing, and monetization. We also incorporated our knowledge about the FinTech phenomenon gained through conferences, presentations, newspaper articles, FinTech start-ups, and discussions with representatives of financial service providers (Nickerson et al. 2013). On this foundation, we identified 24 characteristics along 11 dimensions (i.e. personalization, information exchange, user network, role of IT, hybridization, channel strategy, data type, payment schedule, user's currency, partner's currency, and business cooperation). In all other iterations, we chose the empiricalto-conceptual approach and examined sample FinTech start-ups collected from four sources. To allow for replication, we searched publicly available FinTech start-up databases in the Internet that cover the FinTech market at an international scope and across functional domains. In iteration 2, our source was Paymentandbanking.com (Bajorat 2015), an online blog observing the FinTech market with a focus on German-speaking countries since May 2011. We filtered Bajorat's list for service offerings of consumer-oriented FinTech start-ups and extracted 111 (out of 198) real-life examples. Analyzing these real-life examples, we extended our taxonomy by 11 characteristics along 4 dimensions (i.e. interaction type, data source, time horizon, and data usage). In iteration 3, we drew a random sample of 270 FinTech start-ups (among 878 internationally active companies labeled "FinTech") from CrunchBase (2016), which claims to be the primary source of company intelligence to millions of users comprising hundreds of thousands of start-up entries. As some start-ups focus on business-to-business (B2B) interactions or are no real FinTech start-ups, we filtered the sample for 88 consumeroriented FinTech start-ups, thereof 83 not considered in previous sources. As a result, we revised the dimension "data usage" from two to three characteristics; that is, we split the characteristic "analytical" into "basic analytical" and "advanced analytical." In iteration 4, we extended our sample with two reports: the "FinTech 50" report by Forbes Magazine (Sharf 2015) that contains 50 FinTech start-ups with focus on the US and the "FinTech 100" report by KPMG and H2 Ventures (Toby and Pollari 2015) that includes 50 leading and 50 emerging FinTech start-ups. Both lists contained 72 so far unconsidered consumer-oriented FinTech start-ups. In this iteration, we derived no additional characteristics, as the additional sample confirmed the existing characteristics and dimensions of our taxonomy. Based on the mentioned sources, we are convinced to have a large and cross-functional coverage of the international FinTech market. After the fourth iteration, all objective and subjective ending conditions were met and we agreed on the final set of non-functional characteristics and dimensions.

\section{Taxonomy of FinTech start-up service offerings}

We now present our taxonomy for service offerings of consumer-oriented FinTech start-ups. Table 2 overviews the non-functional dimensions and characteristics included in our taxonomy structured along the perspectives interaction, data, and monetization. Table 2 also indicates whether the dimensions are exclusive or non-exclusive and in which iteration the dimensions were added or revised. As for exclusive dimensions, exactly one characteristic can be observed at a time, such as either "personalized" or "not personalized" in the dimension "personalization". For non-exclusive dimensions, multiple characteristics can be observed in one service offering, such as "user" and "peer" data in the dimension "data source". To develop a future-looking taxonomy, we grounded the exclusiveness of the included dimensions on theoretical possibility instead of on currently observable real-life examples. Below, we introduce the dimensions and non-functional characteristics in detail together with justificatory references. We show an application of our taxonomy in one of the following sections.

\section{Interaction}

The first perspective refers to the interaction between FinTech start-ups and customer. It comprises seven dimensions, i.e., personalization, information exchange, interaction type, user network, role of IT, hybridization, and channel strategy.

- Personalization - Personalization describes the customization of content and content presentation. FinTech startups can provide their users with the possibility to personalize services on their own (Wells and Wolfers 2000; Zhang et al. 2005). If a service is personalized, it can be adapted to the individual needs of a particular user or user group. Not personalized services are offered in a standardized way without significant personalization.

- Information exchange - Information exchange captures how interactions between a FinTech start-up and its users are triggered (Ma 2015; Xu et al. 2010). Pull services provide or exchange information only after the user has accessed the service. Push services inform users regularly or based on events, e.g., with notifications on mobile devices, emails, or text messages.

- Interaction type - The interaction type systematizes the role of FinTech start-ups in the interaction with their users (Chircu and Kauffman 1999). Direct interaction reflects one-on-one service delivery from the FinTech start-up to the user. An intermediary is a service that brings together users with other businesses or with other users. A marketplace is a specific form of an intermediary that explicitly lists the offers of business partners or other users that can be accepted by the users of the FinTech start-up service offering.

- User network - The user network dimension mainly represents the extent to which a service offering enables communication among users of the FinTech service (Lesser and Fontaine 2004). A user network is isolated, if no 
Table 2 Taxonomy of the service offerings of consumer-oriented FinTech start-ups

\begin{tabular}{|c|c|c|c|c|c|c|c|}
\hline Perspective & Dimension & \multicolumn{4}{|c|}{ Characteristics } & $\mathbf{E} / \mathbf{N}^{1}$ & It. $^{2}$ \\
\hline \multirow{7}{*}{ Interaction } & Personalization & \multicolumn{2}{|c|}{ not personalized } & \multicolumn{2}{|c|}{ personalized } & $\mathrm{E}$ & 1 \\
\hline & Information exchange & \multicolumn{2}{|l|}{ pull } & \multicolumn{2}{|r|}{ push } & $\mathrm{N}$ & 1 \\
\hline & Interaction type & Direct & \multicolumn{2}{|c|}{ intermediary } & marketplace & $\mathrm{E}$ & 2 \\
\hline & User network & \multicolumn{2}{|c|}{ isolated } & \multicolumn{2}{|c|}{ interconnected } & $\mathrm{E}$ & 1 \\
\hline & Role of IT & \multicolumn{2}{|c|}{ technology-mediated } & \multicolumn{2}{|c|}{ technology-generated } & $\mathrm{E}$ & 1 \\
\hline & Hybridization & \multicolumn{2}{|c|}{ service-only } & \multicolumn{2}{|c|}{ with physical product } & $\mathrm{E}$ & 1 \\
\hline & Channel strategy & \multicolumn{2}{|c|}{ digital exclusive } & \multicolumn{2}{|c|}{ digital non-exclusive } & $\mathrm{E}$ & 1 \\
\hline \multirow{4}{*}{ Data } & Data source & user & \multicolumn{2}{|c|}{ peer } & public & $\mathrm{N}$ & 2 \\
\hline & Time horizon & historic & \multicolumn{2}{|c|}{ current } & predictive & $\mathrm{N}$ & 2 \\
\hline & Data usage & transactional & \multicolumn{2}{|c|}{ basic analytical } & $\begin{array}{l}\text { advanced } \\
\text { analytical }\end{array}$ & $\mathrm{N}$ & $2+3$ \\
\hline & Data type & \multicolumn{2}{|c|}{ structured } & \multicolumn{2}{|c|}{ unstructured } & $\mathrm{N}$ & 1 \\
\hline \multirow{4}{*}{ Monetization } & Payment schedule & none & \multicolumn{2}{|c|}{ transactional } & subscription & $\mathrm{N}$ & 1 \\
\hline & User's currency & attention & \multicolumn{2}{|c|}{ data } & money & $\mathrm{E}$ & 1 \\
\hline & Partner's currency & \multicolumn{2}{|l|}{ none } & \multicolumn{2}{|c|}{ money } & $\mathrm{E}$ & 1 \\
\hline & Business cooperation & \multicolumn{2}{|c|}{ stand-alone } & \multicolumn{2}{|c|}{ ecosystem } & $\mathrm{E}$ & 1 \\
\hline
\end{tabular}

${ }^{1} \mathrm{E}=$ Exclusive dimension (one characteristic observable at a time); $\mathrm{N}=$ Non-exclusive dimension (potentially multiple characteristics observable at a time ${ }^{2}$ Iteration in which the dimension was added or revised

communication is enabled between individual users. Services with an interconnected user network facilitate the exchange among users through a user community or interuser contacts.

- Role of IT - Froehle and Roth (2004) differentiate five archetypes of technology in service encounters. As we consider technology-driven FinTech start-up services, only face-to-screen contact is relevant to the interaction between users and FinTech start-ups. In technologymediated service encounters, users and service agents are not co-located, but their interaction is carried out via technology. Technology-generated means that no service agent is directly involved.

- Hybridization - The hybridization dimension refers to the FinTech start-up's possibility of offering bundles of physical products and services that are called hybrid products (Berkovich et al. 2009; Park et al. 2012). If the Fintech service is provided with a physical product, a physical product (e.g., a credit card required to handle transactions) is integrated in the core service offering. Service-only means that no physical thing is required for service delivery beyond a mere access point to the Internet such as a smartphone or a Desktop PC.

- Channel strategy - The channel through which a FinTech start-up offers its service is captured by the channel strategy dimension. All FinTech start-ups use digital channels, but their services can also be delivered in a multichannel way (O'Sullivan et al. 2002; Sousa and Voss 2006). Digital exclusive FinTech services restrict interactions to digital channels, e.g. an Internet website or Mobile app. Digital non-exclusive services allow for using parts of the FinTech service without digital channels.

\section{Data}

The second perspective characterizes the processing of data by FinTech start-ups. This perspective comprises four dimensions, i.e., data source, time horizon, data usage, and data type.

- Data source - The data source dimension differentiates service offerings of FinTech start-ups by the data sources they use (Janssen et al. 2012; Linoff and Berry 2002). User data relates to personal, transactional, and behavioral data of individual users, whereas peer data refers to the data of other users or customers. Public data covers data that is not directly related to users or customers such as open data.

- Time horizon - The time horizon of data involved in FinTech services ranges from historic over current data to future or predictive data (Armstrong 2002). Transaction histories or historic stock trends are examples of historic data, whereas user inputs and results of data processing represent current data. Predictive data result from analyzing current and historic data with statistical techniques.

- Data usage - The data usage dimension distinguishes whether FinTech start-up service offerings process data transactionally or analytically (Bose 2009). Transactional data usage means that data are primarily processed for a single transaction. We refer to basic 
analytical as the use of filters, aggregations, simple calculations, comparisons, and techniques of similar analytical intensity. Advanced analytical represents the use of more sophisticated methods such as prediction models, complex calculations, clustering, and comparable methods.

- Data type - The data type dimension reflects that FinTech start-up service offerings process data with different formats and degrees of structure (Baars and Kemper 2008; Weglarz 2004). Structured data correspond to data with predetermined types and well-defined relationships (e.g. normalized database schemas). Unstructured data, in contrast, comprise full-text documents without further semantics, images, videos, or audio files.

\section{Monetization}

The third perspective describes how FinTech start-ups monetize their service offering. It comprises four dimensions, i.e., payment schedule, user's currency, partner's currency, and business cooperation.

- Payment schedule - The payment schedule dimension differentiates the regularity of payments from users or business partners. Alternatively, a service offering can be free of charge (Fishburn and Odlyzko 1999; O'Sullivan et al. 2002; Postmus et al. 2009). With a transactional payment schedule, money is charged based on the actual usage of a FinTech service. In case of a subscription model, a fixed fee is charged per unit time regardless of actual usage. If the service offering is free of charge, then the payment schedule is classified as none.

- User's currency - In the FinTech context, users need not necessarily pay with money to use a service. For instance, a FinTech start-up can implement a two-sided market and incorporate two value delivery systems with different pricing strategies. This results in valuable cross-side network effects for the two-side service provider. The user's currency dimension covers the currency with which the users pays for using a service (Baden-Fuller and Haefliger 2013; Eisenmann et al. 2006; Rysman 2009). FinTech start-ups can monetize their services by offering users' attention to business partners such as advertisers or to other fee-based services within and without the start-up. If the user's currency is data, then the service monetizes user data within or without the FinTech start-up. However, the service can also be monetized by letting users pay with their money.

- Partner's currency -FinTech start-ups partnering with another business can monetize their services by offering the attention or data of its users to this business partner. The partner's currency dimension represents if and how a business partner pays to the FinTech start-up (Baden-Fuller and Haefliger 2013; Eisenmann et al. 2006; Rysman
2009). Business partners, such as advertisers or vendors that benefit from user data or an attractive user base, can compensate the FinTech start-up with money. In case there is no business partner involved in the core service offering that pays money to the FinTech start-up, the partner's currency is none.

- Business cooperation - The business cooperation dimension indicates if a FinTech start-up operates on its own or if it collaborates with partners such as traditional financial service providers (Bharadwaj et al. 2013; Iansiti and Levien 2004; Lusch and Nambisan 2013; Moore 1996). Stand-alone service offerings of FinTech start-ups do not maintain a business cooperation, whereas the co-creation of value as one actor among interdependent other actors in a business cooperation that sometimes even crosses traditional industry boundaries is described as ecosystem.

\section{Application of the taxonomy}

\section{Classification of real-life examples}

To demonstrate the applicability and usefulness of our taxonomy, we classified the service offerings of all 227 consumeroriented FinTech start-ups that we used to create the taxonomy. The definition of characteristics and dimensions from the preceding section served as a codebook for the classification. To ensure quality, all authors discussed the classification of randomly drawn examples, extreme examples, and ambiguous examples of service offerings and revised the codebook where necessary. Based on this common and codified understanding, the classification of the remaining cases was mainly performed by a single author. In an ex-post quality check, a random 5\% sample of our total set of start-ups was individually coded by each of the three authors and the results were compared. An inter-coder reliability of $87.3 \%$ as percent agreement or $73.3 \%$ as Fleiss' (1971) kappa equally weighted among all dimensions suggests adequate data quality. Landis and Koch (1977) denote a Fleiss' (1971) kappa between 61\% and $80 \%$ as "substantial" strength of agreement among all coders. Thus, we proceed with the analysis based on the coding. Table 3 shows the relative frequency of all characteristics.

Referring to the relative frequencies of non-functional characteristics among real-life examples shown in Table 3, we had to deal with publicly unavailable information that resulted in missing values (14\% missing for "user's currency," $15 \%$ for "partner's currency," $19 \%$ for "payment schedule," and 1 missing value $(1 \%)$ in each of the dimensions "information exchange," "user network," "data source," and "time horizon of data"). Due to these missing values, which we do not consider for further interpretation, fractions of the characteristics in the affected dimensions can be even higher than observed. 
When analyzing the statistics from Table 3, some notable observations can be made: Over one third (39\%) of all investigated FinTech start-ups personalize their service offerings to serve their users individually. In line with Amazon's CEO Jeff Bezos' aim to build an individual online shop for each customer (Walker 1998), those FinTech start-ups strive for individual customer experience. Further, it is noteworthy that $76 \%$ of all considered service offerings were technology-generated; that is, no human employee is directly involved in service delivery of more than three quarters of all investigated FinTech start-ups. As for channel strategy, almost all (99\%) FinTech start-ups exclusively use digital channels. An example for a FinTech start-up that also uses non-digital channels is MK Payment Solutions. You can redeem their prepaid vouchers purchased in a physical shop during offline shopping without needing to redeem them online. However, the offline channel is just a supplement to online redemption. Despite the availability of big data, smart data, and advanced analytics, we were surprised that less than one third of all analyzed FinTech start-ups apply basic (21\%) or advanced (9\%) analytics. While all FinTech start-ups use current data, only $8 \%$ use predictive data. Finally, it is not surprising that the majority (93\%) of FinTech start-ups process user data, but it is meaningful that they process mostly structured data $(97 \%)$, with unstructured data representing only $3 \%$ of all cases. In almost half $(43 \%)$ of all cases, the user pays for the service with money. Nevertheless, in one third (33\%) of all cases, FinTech start-ups monetize their service offerings through third-party companies instead of or additional to forcing users to pay for the service.

In sum, the service offerings of today's FinTech start-ups have very diverse configuration across our taxonomy's 15 dimensions. With the application of cluster analysis below, we take an aggregated perspective on the non-functional characteristics included in our taxonomy and infer high-level insights.

\section{Clusters of FinTech start-up service offerings}

\section{Methodological considerations}

To identify archetypes among the collected real-life examples of FinTech start-up service offerings, we applied cluster analysis. Cluster analysis is a statistical technique to group similar objects based on their characteristics (Field 2013; Hair et al. 2010). The aim of this technique is to achieve high homogeneity within each cluster and high heterogeneity among objects of different clusters (Bacher et al. 2010; Backhaus et al. 2011; Cormack 1971). We chose Ward's (1963) algorithm, which is an agglomerative hierarchical clustering approach often used in practical applications (Backhaus et al. 2011; Ferreira and Hitchcock 2009; Fraley and Raftery 2002; Milligan 1980; Milligan and Cooper 1988; Saraçli et al. 2013). Whereas partitioning clustering algorithms start with a given number of clusters and proceed by mapping all objects to clusters until a given function reaches its optimum, hierarchical clustering algorithms generate solutions for all possible numbers of clusters by subsequently merging (agglomerative type) or dividing (divisive type) clusters (Backhaus et al. 2011).

Among the distance measures suitable for binary variables, we selected the matching coefficient (Sokal and Michener

Table 3 Relative frequencies of the non-functional characteristics among the service offerings of 227 consumer-oriented FinTech start-ups

\begin{tabular}{|c|c|c|c|c|c|}
\hline Perspective & Dimension & \multicolumn{4}{|l|}{ Characteristics } \\
\hline \multirow{7}{*}{ Interaction } & Personalization & \multicolumn{2}{|c|}{ not personalized $(61 \%)$} & \multicolumn{2}{|c|}{ personalized $(39 \%)$} \\
\hline & Information exchange & \multicolumn{2}{|c|}{ pull $(99 \%)$} & \multicolumn{2}{|c|}{ push $(22 \%)$} \\
\hline & Interaction type & $\operatorname{direct}(28 \%)$ & \multicolumn{2}{|c|}{ intermediary $(54 \%)$} & marketplace $(18 \%)$ \\
\hline & User network & \multicolumn{2}{|c|}{ isolated $(78 \%)$} & \multicolumn{2}{|c|}{ interconnected (21\%) } \\
\hline & Role of IT & \multicolumn{2}{|c|}{ technology-mediated $(24 \%)$} & \multicolumn{2}{|c|}{ technology-generated $(76 \%)$} \\
\hline & Hybridization & \multicolumn{2}{|c|}{ service-only $(89 \%)$} & \multicolumn{2}{|c|}{ with physical product $(11 \%)$} \\
\hline & Channel strategy & \multicolumn{2}{|c|}{ digital exclusive $(99 \%)$} & \multicolumn{2}{|c|}{ digital non-exclusive (1\%) } \\
\hline \multirow{4}{*}{ Data } & Data source & user $(93 \%)$ & \multicolumn{2}{|c|}{ peer $(26 \%)$} & public $(51 \%)$ \\
\hline & Time horizon & historic $(64 \%)$ & \multicolumn{2}{|c|}{ current $(100 \%)$} & predictive $(8 \%)$ \\
\hline & Data usage & $\begin{array}{c}\text { transactional } \\
(87 \%)\end{array}$ & \multicolumn{2}{|c|}{$\begin{array}{c}\text { basic analytical } \\
(21 \%)\end{array}$} & $\begin{array}{c}\text { advanced } \\
\text { analytical }(9 \%)\end{array}$ \\
\hline & Data type & \multicolumn{2}{|c|}{ structured $(97 \%)$} & \multicolumn{2}{|c|}{ unstructured $(3 \%)$} \\
\hline \multirow{4}{*}{ Monetization } & Payment schedule & none $(11 \%)$ & \multicolumn{2}{|c|}{ transactional $(44 \%)$} & subscription $(29 \%)$ \\
\hline & User's currency & attention $(35 \%)$ & \multicolumn{2}{|c|}{ data $(8 \%)$} & money $(43 \%)$ \\
\hline & Partner's currency & \multicolumn{2}{|c|}{ none $(52 \%)$} & \multicolumn{2}{|c|}{ money $(33 \%)$} \\
\hline & Business cooperation & \multicolumn{2}{|c|}{ stand-alone $(85 \%)$} & \multicolumn{2}{|c|}{ ecosystem $(15 \%)$} \\
\hline
\end{tabular}

Cumulated relative frequencies can be different from $100 \%$ if a dimension is non-exclusive or in case of missing data 
1958) rather than more complex measures like the Russel/Rao index (Rao 1948) or the Jaccard coefficient (P. H. A. Sneath 1957) as it is the most straightforward approach, fits the substantive interpretation of our data, is commonly used in combination with Ward's method and has shown to perform similar to other measures of distance or similarity (Finch 2005; Hands and Everitt 1987). To apply the distance measure, we dichotomized our classification that each characteristic of a dimension is represented by a separate column that indicates 1 if the characteristic is observable at the respective service offering and 0 if not. Subsequently, we standardized all dimensions in a way that the distance between two service offerings lays between 0 and 1 for each dimension. We follow methodological guidelines like, for example, Finch (2005) who performed a simulation study and tested the application of Ward's algorithms in combination with different distance measures, thereunder the matching coefficient, on dichotomous data. Finch $(2005$, p. 97) asserts with respect to the combination of dichotomous data, matching coefficient, and Ward's method that " $[. .$.$] results would support the notion$ that cluster analysis of dichotomous data using these approaches is appropriate, and can be expected to work reasonably well."

Despite tremendous research in the fields of cluster validation and measures for determining the suitable number of clusters, there are no clear recommendations for one best suitable measure (Wu 2012). For instance, Backhaus et al. (2011), Milligan and Cooper (1985), and Sneath and Sokal (1973) describe the decision between different cluster solutions (i.e., number of clusters) as a trade-off between the manageability of the cluster solution and homogeneity within each cluster. To determine a suitable number of clusters, we considered 13 different measures as listed in the Appendix (Tables 6 and 7). According to these measures, the number of clusters ranges from 1 to 14 . As no clear number of clusters is perceptible, we grouped all dimensions according to the perspectives interaction, data, or monetization and repeated the cluster analysis for each perspective separately. To ensure manageability, we limited the number of clusters to the number of dimensions for each perspective and considered the interpretability of the suggested cluster solutions when deciding the number of clusters. We used a three-cluster solution for interaction and monetization and the two-cluster solution for data. Table 4 presents the archetypes as cluster solutions for each perspective as well as the absolute and relative frequency of characteristics in each archetype.

Finally, we created contingency tables (Table 5) across the perspective-specific archetypes, in which we used Pearson's chi-squared test of independence to examine dependencies among all possible combinations of the three perspectives (Agresti 2007). Partially considering comparatively small cluster sizes with only 18 or 38 observations (e.g., the advanced analytics data archetype), we use a significance level of 0.1 . For precision of the tests and given the cell sizes of the contingency tables, we derive $p$-values via Monte Carlo simulation (Hope 1968). When the test indicates stochastic dependence between two perspectives ( $p$-value $\leq 0.1$ ), the mapping of a FinTech start-up service offering to an archetype in one perspective relates to an archetype in another perspective. Hence, there are typical combinations of archetypes. When the test indicates stochastic independence between two perspectives, there are no statistically significant relationships between the archetypes in both perspectives.

\section{Cluster solution and interpretation}

The results of the cluster analysis are three archetypes in the interaction perspective, three in the monetization perspective, and two in the data perspective. For the cluster solution of the interaction perspective, goodness-of-fit measures state a total sum-of-squares of 682.0 (error sum-of-square of 369.4 and $\mathrm{R}^{2}$ of 0.46$)$. For the data perspective the total sum-of-squares is 118.3 (error sum-of-squares of 93.9 and $\mathrm{R}^{2}$ of 0.21 ) and for the monetization perspective the total sum-of squares is 405.4 (error sum-of-squares of 139.4 and $\mathrm{R}^{2}$ of 0.66 ). According to these goodness-of-fit measures, the archetypes of the data perspective have the lowest $\mathrm{R}^{2}$ and are therefore less significant compared to the higher $\mathrm{R}^{2}$ of the interaction and monetization archetypes. For each archetype, Table 4 states absolute and relative frequencies of the characteristics among 227 real-life examples.

The interaction perspective comprises three archetypes: "personalized isolated," "non-personalized isolated," and "socially connecting intermediate." All archetypes contain FinTech start-ups mainly featuring pull-based information exchange. In particular, personalized user interaction $(100 \%)$ and a not interconnected user base (91.4\%) predominantly describe the personalized isolated archetype. In comparison, the nonpersonalized isolated archetype mainly differs by very rare personalization (3.4\%). The socially connecting intermediate interaction archetype is characterized by an interconnected user network (94.7\%) and push-based information exchange (55.3\%).

The data perspective comprises two archetypes: "standard processing" and "advanced analytics." Both archetypes mainly use structured data from users, but only $5.6 \%$ to $27.3 \%$ use peer data and around $50 \%$ to $60 \%$ publicly available data. The standard processing archetype contains most FinTech start-ups from our sample. They typically use current data $(99.5 \%)$ in a transactional way (93.8\%) together with basic analytical functions $(23.0 \%)$. With a size of 18 start-ups, the advanced analytics archetype encompasses FinTech start-ups whose service offerings include advanced analytical data processing $(100.0 \%)$.

The monetization perspective comprises three archetypes: "no money," "user-paid," and "business-paid." It suffers from some missing values due to little available pricing information for some FinTech start-up services. However, the no money archetype typically involves no paying business partner, and users only pay with their attention and loyalty or their data but 
Table 4 Archetypes of 227 real-life consumer-oriented FinTech start-up service offerings

\begin{tabular}{|c|c|c|c|c|c|c|}
\hline \multicolumn{7}{|l|}{ Interaction } \\
\hline Archetype & \multicolumn{2}{|l|}{ Dimension } & \multicolumn{4}{|l|}{ Characteristics } \\
\hline \multirow{7}{*}{$\begin{array}{l}\text { Personalized } \\
\text { isolated } \\
(n=70)\end{array}$} & \multicolumn{2}{|c|}{ Personalization } & \multicolumn{2}{|c|}{ not personalized [0] $(0.0 \%)$} & \multicolumn{2}{|c|}{ personalized [70] $(100.0 \%)$} \\
\hline & \multicolumn{2}{|c|}{ Information exchange } & \multicolumn{2}{|c|}{ pull [68] $(97.1 \%)$} & \multicolumn{2}{|c|}{ push [19] $(27.1 \%)$} \\
\hline & \multicolumn{2}{|c|}{ Interaction type } & direct [33] $(47.1 \%)$ & \multicolumn{2}{|c|}{ intermediary [31] $(44.3 \%)$} & marketplace [6] (8.6\%) \\
\hline & \multicolumn{2}{|c|}{ User network } & \multicolumn{2}{|c|}{ isolated [64] $(91.4 \%)$} & \multicolumn{2}{|c|}{ interconnected $[5](7.1 \%)$} \\
\hline & \multicolumn{2}{|l|}{ Role of IT } & \multicolumn{2}{|c|}{ technology-mediated [12] (17.1\%) } & \multicolumn{2}{|c|}{ technology-generated [58] (82.9\%) } \\
\hline & \multicolumn{2}{|c|}{ Hybridization } & \multicolumn{2}{|c|}{ service-only [68] $(97.1 \%)$} & \multicolumn{2}{|c|}{ with physical product [2] (2.9\%) } \\
\hline & Channel strate & & digital exclusive [7 & $(100.0 \%)$ & digital $\mathrm{r}$ & n-exclusive $[0](0.0 \%)$ \\
\hline & Personalizatic & & not personalized [1 & $(96.6 \%)$ & pers & nalized [4] (3.4\%) \\
\hline & Information es & change & pull [119] (10 & $0 \%)$ & & ush [11] (9.2\%) \\
\hline Non- & Interaction tyl & & direct [27] $(22.7 \%)$ & intermediar & (47.9\%) & marketplace [35] (29.4\%) \\
\hline $\begin{array}{l}\text { personalized } \\
\text { isolated }\end{array}$ & User network & & isolated [112] & $.1 \%)$ & inter & onnected [7] (5.9\%) \\
\hline$(n=119)$ & Role of IT & & technology-mediated & 9] $(24.4 \%)$ & technolog & -generated [90] (75.6\%) \\
\hline & Hybridization & & service-only $[101$ & $84.9 \%)$ & with phys & cal product [18] (15.1\%) \\
\hline & Channel strate & & digital exclusive [1 & $(98.3 \%)$ & digital $\mathrm{n}$ & n-exclusive [2] (1.7\%) \\
\hline & Personalizatic & & not personalized [2 & $(63.2 \%)$ & persc & lalized [14] (36.8\%) \\
\hline & Information es & change & pull $[38](10$ & & & $\operatorname{sh}[21](55.3 \%)$ \\
\hline Socially & Interaction typ & & direct [3] $(7.9 \%)$ & intermediar & ] $(92.1 \%)$ & marketplace [0] $(0.0 \%)$ \\
\hline $\begin{array}{l}\text { connecting } \\
\text { intermediate }\end{array}$ & User network & & isolated [2] & $\%)$ & interc & nnected [36] $(94.7 \%)$ \\
\hline$(n=38)$ & Role of IT & & technology-mediated & 3] $(34.2 \%)$ & technolog & -generated [25] $(65.8 \%)$ \\
\hline & Hybridization & & service-only $[33$ & $86.8 \%)$ & with phy & ical product [5] $(13.2 \%)$ \\
\hline & Channel strate & & digital exclusive [3 & $(100.0 \%)$ & digital $\mathrm{n}$ & n-exclusive [0] $(0.0 \%)$ \\
\hline Data & & & & & & \\
\hline Archetype & Dimension & Chara & eristics & & & \\
\hline & Data source & & r [202] $(96.7 \%)$ & peer [57] (2 & & public [104] $(49.8 \%)$ \\
\hline & Time horizon & hist & ric [130] $(62.2 \%)$ & urrent [208] & & predictive [14] (6.7\%) \\
\hline $\begin{array}{l}\text { processing } \\
(n=209)\end{array}$ & Data usage & & $\begin{array}{l}\text { transactional } \\
196](93.8 \%)\end{array}$ & $\begin{array}{l}\text { basic analy } \\
\text { [48] (23. }\end{array}$ & & $\begin{array}{c}\text { advanced analytical } \\
{[3](1.4 \%)}\end{array}$ \\
\hline & Data type & & structured [209] (100.0 & & unstru & ured [24] $(11.5 \%)$ \\
\hline & Data source & & \begin{tabular}{l|l}
$\operatorname{er}[10](55.6 \%)$ & \\
\end{tabular} & peer $[1](5$ & & public [11] $(61.1 \%)$ \\
\hline Advanced & Time horizon & his & oric [15] (83.3\%) & urrent [18] ( & & predictive [4] (22.2\%) \\
\hline $\begin{array}{l}\text { analytics } \\
(n=18)\end{array}$ & Data usage & & \begin{tabular}{l|l} 
transactional & \\
{$[2](11.1 \%)$}
\end{tabular} & $\begin{array}{r}\text { basic anal } \\
{[0](0.0}\end{array}$ & & $\begin{array}{c}\text { advanced analytical } \\
{[18](100.0 \%)}\end{array}$ \\
\hline & Data type & & structured [18] (100.0 & & unstru & tured [3] $(16.7 \%)$ \\
\hline Monetizatio & & & & & & \\
\hline Archetype & Dimension & & Characteristics & & & \\
\hline & Payment sche & & none [24] $(51.1 \%)$ & transactio & $(0.0 \%)$ & subscription $[0](0.0 \%)$ \\
\hline No money & User's curren & & attention [18] $(38.3 \%)$ & data [ & $2.8 \%)$ & money $[0](0.0 \%)$ \\
\hline$(n=47)$ & Partner's curr & ency & none [24] (5 & & & oney [0] $(0.0 \%)$ \\
\hline & Business coop & ration & stand-alone [47] & $00.0 \%)$ & & system $[0](0.0 \%)$ \\
\hline & Payment sche & & none [0] $(0.0 \%)$ & transaction & ]$(50.0 \%)$ & "subscription [52] (53.1\%) \\
\hline User-paid & User's curren & & attention [0] $(0.0 \%)$ & data [ & $0 \%)$ & money [98] $(100.0 \%)$ \\
\hline$(n=98)$ & Partner's curr & ency & none [93] (9 & & & oney [3] $(3.1 \%)$ \\
\hline & Business coop & ration & stand-alone [88] & $9.9 \%)$ & eco & stem [10] (10.2\%) \\
\hline & Payment sche & & "none [2] $(2.4 \%)$ & transaction & ]$(61.0 \%)$ & "subscription [13] (15.9\%) \\
\hline Business- & User's curren & & attention [62] (75.6\%) & data $[1$ & $.9 \%)$ & money $[0](0.0 \%)$ \\
\hline $\begin{array}{l}\text { paid } \\
(n=82)\end{array}$ & Partner's curr & ency & none [1] (1. & & & ney [71] $(86.6 \%)$ \\
\hline & Business coop & ration & stand-alone [59] & $2.0 \%)$ & eco & stem [23] $(28.0 \%)$ \\
\hline
\end{tabular}

$[\ldots]=$ Absolute frequency; $(\ldots)=$ Relative frequency; Cumulated relative frequencies can be different from $100 \%$ if a dimension is non-exclusive or in case of missing data 
Table 5 Contingency tables and Pearson's chi-squared test of independence among the archetypes of all three perspectives $(n=227$ for each sub-table)

Contingency table for perspectives data and interaction

\begin{tabular}{|c|c|c|c|c|c|}
\hline & & $\begin{array}{l}\text { Interaction } \\
\text { Personalized isolated }\end{array}$ & Non-personalized isolated & $\begin{array}{l}\text { Socially } \\
\text { connecting intermediate }\end{array}$ & $\begin{array}{l}\text { Pearson's chi-squared } \\
\text { test of independence }\end{array}$ \\
\hline \multirow[t]{2}{*}{ Data } & Standard processing & 61 & 110 & 38 & $\chi^{2}=5.623$ \\
\hline & Advanced analytics & 9 & 9 & 0 & $\mathrm{p}$-value $=0.053$ \\
\hline \multicolumn{6}{|c|}{ Contingency table for perspectives monetization and interaction } \\
\hline \multirow{4}{*}{ Monetization } & & $\begin{array}{l}\text { Interaction } \\
\text { Personalized isolated }\end{array}$ & Non-personalized isolated & Socially connecting intermediate & $\begin{array}{l}\text { Pearson's chi-squared } \\
\text { test of independence }\end{array}$ \\
\hline & No money & 17 & 17 & 13 & $\chi^{2}=8.781$ \\
\hline & User-paid & 27 & 55 & 16 & $\mathrm{p}$-value $=0.058$ \\
\hline & Business-paid & 26 & 47 & 9 & \\
\hline \multicolumn{6}{|c|}{ Contingency table for perspectives data and monetization } \\
\hline \multirow{3}{*}{ Data } & & $\begin{array}{l}\text { Monetization } \\
\text { No money }\end{array}$ & User-paid & Business-paid & $\begin{array}{l}\text { Pearson's chi-squared } \\
\text { test of independence }\end{array}$ \\
\hline & Standard processing & 42 & 89 & 78 & $\chi^{2}=1.730$ \\
\hline & Advanced analytics & 5 & 9 & 4 & $\mathrm{p}$-value $=0.451$ \\
\hline
\end{tabular}

not (yet) with real money. FinTech start-ups of this archetype offer their service stand-alone (100.0\%); that is, they are not organized in a business ecosystem. The user-paid archetype involves no paying business partner $(94.9 \%)$, but the user pays with money for the service delivery (100.0\%), either in a transactional way or within a subscription. Further, only a limited number of FinTech start-ups of this archetype are organized in a business ecosystem (10.2\%). FinTech start-ups of the business-paid archetype are sometimes organized in a business ecosystem (28.0\%) but are mostly stand-alone (72.0\%). It involves a paying business partner $(86.6 \%)$ and demands attention $(75.6 \%)$ or data $(15.9 \%)$ from users only.

In conclusion, the archetypes of the interaction perspective mainly distinguish FinTech start-up service offerings by the degree of personalization and interconnectedness of the user network. Summarizing the archetypes of the data perspective, FinTech start-up service offerings mainly differ by the use of sophisticated data analytics methods that are currently observed only to a small extent. Interpreting the archetypes of the monetization perspective, FinTech start-up service offerings can mainly be distinguished by the role (none, user, or business partner) that pays for the service delivery.

Table 5 shows contingency tables among the archetypes of all pairs of perspectives. The chi-squared test of independence indicates that archetypes of the data and interaction perspectives depend on each other another ( $p$-value 0.053 ). The socially connecting intermediate interaction archetype is not observed with the advanced analytics data archetype, although this setting occurs for the personalized and non-personalized isolated interaction archetypes $(12.9 \%$ and $7.6 \%$ of the observations, respectively).
The test results further suggest dependence between the archetypes of the monetization and interaction perspectives ( $p$ value 0.058 ). The socially connecting intermediate interaction archetype occurs comparatively less with the business-paid monetization archetype (23.7\% compared with $37.1 \%$ and $39.5 \%$, respectively, for personalized and non-personalized isolated interaction archetypes).

Archetypes of the data and monetization perspectives seem to be independent ( $p$-value 0.451). This means that the observed archetype of a FinTech start-up service offering in the data perspective is independent from that in the monetization perspective. The advanced analytics data archetype contains only a few observations overall, but the distribution across monetization archetypes follows the same pattern as for the standard processing data archetype. Summarized, typical combinations of archetypes among the three perspectives interaction, data, and monetization exist, however, not between every pair.

\section{Discussion}

Our study contributes to the descriptive knowledge on the FinTech phenomenon, as it explores a not yet well-understood domain. Our main contribution is a theoretically well-founded and empirically validated taxonomy that focuses on the nonfunctional characteristics of consumer-oriented FinTech start-up service offerings. The comprehensive view of our taxonomy complements existing functionally oriented FinTech classifications. Although functional classifications help distinguish FinTech start-ups based on what they do for customers, they abstract from the mechanics underlying FinTech start-up service offerings and from how service offerings can be configured. Our 
taxonomy is the first to take a non-functional perspective. From a theoretical point of view, our taxonomy serves as foundation for the analysis, design, and configuration of FinTech start-up service offerings, the analysis of antecedents of FinTech success, and the adoption of service offerings. Further, archetypes in each of the three perspectives interaction, data, and monetization represent reoccurring patterns in the variety of service offerings. Those archetypes can be used as a starting point to understand higher-order configurations of FinTech start-up service offerings and to anticipate comparable trends in other consumer-oriented industries.

As with every research project, our study is beset with limitations. First, our sample of FinTech start-ups is not exhaustive, as there are over 12,000 FinTech companies worldwide offering traditional and new services (Dietz et al. 2015). We tried to address this issue by referring to different FinTech reports and drawing a random sample from the extensive start-up database CrunchBase. Second, our samples sample only includes extant FinTech start-ups, but the start-up landscape is highly dynamic. Emerging types of FinTech services may be underrepresented in the current sample. For example, we assume that business ecosystems and the use of advanced data analytics will be observed more often in the future. Therefore, we developed our taxonomy to be revisable and extendible by new perspectives, characteristics, and dimensions, as suggested by Nickerson et al. (2013). Third, our taxonomy only considers consumer-oriented FinTech start-ups. To understand the FinTech phenomenon at large, B2B FinTech start-ups and FinTech services offered by incumbents should be considered as well.

Despite these limitations, our study entails a range of managerial implications. First, our taxonomy provides practitioners with a differentiated view on the configuration of FinTech start-up service offerings beyond a functional or technological perspective. Practitioners such as traditional financial service providers get a detailed understanding of the interaction among FinTech start-ups and their customers, learn how FinTech start-ups employ data analytics to enable innovative financial services, and get to know different ways of monetizing a FinTech service. On this foundation, practitioners can analyze an individual FinTech start-up service offering, design new service configurations, and compare existing competitive and non-competitive service offerings within and across functional domains. As for our cluster analysis, we identified archetypes that capture reoccurring configurations of service offerings. We identified "personalized isolated," "non-personalized isolated," and "socially connecting intermediate" as interaction-related archetypes, "standard processing" and "advanced analytics" within the data perspective, and "no money," "user-paid," and "business-paid" as monetization-related archetypes. These archetypes provide practitioners with an aggregated view on FinTech start-up service offerings. Lastly, we addressed the consumer's role in FinTech services when we showed that the roles of users and customers diverge as alternative ways of monetization emerge (i.e., a business-paid monetization scheme where the user's data is monetized).

\section{Conclusion and further research}

Against the increasing importance of FinTech start-ups for the financial sector, we investigated non-functional characteristics of consumer-oriented FinTech start-up service offerings. To do so, we developed a taxonomy, following an established taxonomy development process. Contributing to the descriptive knowledge on FinTech start-ups, our taxonomy characterizes FinTech start-up service offerings based on 15 dimensions structured along the perspectives interaction, data, and monetization. By applying our taxonomy to 227 real-world examples, we demonstrated that it helps analyze and understand FinTech start-up service offerings. For each perspective, we also identified archetypes, i.e., typical combinations of characteristics across all included dimensions.

Our results also motivate future research. First, researchers should further explore the configuration of FinTech start-up service offerings. Second, the relationships between different configurations and the success of FinTech start-ups should be examined. Third, researchers should investigate the service offerings of B2B FinTech start-ups as we only focused on consumer-oriented start-ups. Our taxonomy could serve as a starting point as we expect similar dimensions in the data and interaction perspectives, while anticipating modifications in the monetization perspective. We hypothesize that the dataoriented archetypes can also be observed in the B2B segment. Although the interaction-related archetypes are likely to have $\mathrm{B} 2 \mathrm{~B}$ equivalents as well, we think that the personalization dimension should be interpreted as individualization for each business partner. We expect most differences in the monetization perspective where the split between users' and business partners' currency may merge into a single dimension. We also suggest to re-interpret the "business cooperation" dimension by differentiating ecosystems into an asymmetric and symmetric cooperation model. Asymmetric cooperation refers to relationships with dedicated service provider and requester roles, whereas symmetric cooperation relates to a strong focus on value co-creation by two or more business partners. We encourage researchers to evaluate a sample of FinTech startups from the B2B segment and test our hypotheses. As traditional financial institutions begin to engage in partnerships with FinTech start-ups and derive best-practices for offering FinTech services on their own, an investigation of the service offerings of traditional financial institutions can be interesting as well. Last not least, we suggest reassessing the dimensions of our taxonomy and clustering results after a certain amount of time, because this will provide valuable longitudinal insights into the evolution of the FinTech phenomenon. 


\section{Appendix}

\section{FinTech start-up sample}

Table 6 FinTech start-up sample with name, website URL, and source for each start-up

\begin{tabular}{|c|c|c|c|c|c|c|}
\hline \multirow[t]{2}{*}{ ID } & \multicolumn{2}{|l|}{ FinTech start-up } & \multicolumn{4}{|l|}{ Source } \\
\hline & Name & Website & Bajorat (2015) & CrunchBase (2016) & Sharf (2015) & Toby and Pollari (2015) \\
\hline 1 & Achieve Lending & achievelending.com & & $\mathrm{x}$ & & \\
\hline 2 & Acorns & acorns.com & & $\mathrm{x}$ & $\mathrm{x}$ & $\mathrm{x}$ \\
\hline 3 & Affirm & affirm.com & & $\mathrm{x}$ & $\mathrm{x}$ & $\mathrm{x}$ \\
\hline 4 & appsichern & appsichern.de & $\mathrm{x}$ & & & \\
\hline 5 & Arthena & arthena.com & & $\mathrm{x}$ & & \\
\hline 6 & Atom Bank & atombank.co.uk & & $\mathrm{x}$ & & $\mathrm{x}$ \\
\hline 7 & auxmoney & auxmoney.com & $\mathrm{x}$ & & & \\
\hline 8 & Avant & avant.com & & $\mathrm{x}$ & $\mathrm{x}$ & $\mathrm{x}$ \\
\hline 9 & avuba & avuba.de & $\mathrm{x}$ & & & \\
\hline 10 & ayondo & ayondo.com & $\mathrm{x}$ & $\mathrm{x}$ & & \\
\hline 11 & Azimo & azimo.com & $\mathrm{x}$ & $\mathrm{x}$ & & \\
\hline 12 & BankingCheck & bankingcheck.de & $\mathrm{x}$ & & & \\
\hline 13 & Bankless24 & bankless24.de & $\mathrm{x}$ & & & \\
\hline 14 & barpay & ezv-gmbh.de/produkte.html & $\mathrm{x}$ & & & \\
\hline 15 & Barzahlen & barzahlen.de & $\mathrm{x}$ & & & \\
\hline 16 & BATS Global Markets & batstrading.com & & $\mathrm{x}$ & & \\
\hline 17 & Bergfürst & de.bergfuerst.com & $\mathrm{x}$ & & & \\
\hline 18 & Betterment & betterment.com & & & $\mathrm{x}$ & $\mathrm{x}$ \\
\hline 19 & bettervest & bettervest.de & $\mathrm{x}$ & & & \\
\hline 20 & Billpay & billpay.de & $\mathrm{x}$ & & & \\
\hline 21 & bitbit & bitbit.cash & & $\mathrm{x}$ & & \\
\hline 22 & Bitbond & bitbond.com & $\mathrm{x}$ & & & \\
\hline 23 & bitcoin.de & bitcoin.de & $\mathrm{x}$ & & & \\
\hline 24 & Bitt & bitt.com & & $\mathrm{x}$ & & \\
\hline 25 & Börsenampel & boersenampel.com & $\mathrm{x}$ & & & \\
\hline 26 & Bridg & bridgtheapp.com & & $\mathrm{x}$ & & \\
\hline 27 & buybitcoin & buybitcoin.ph & & $\mathrm{x}$ & & \\
\hline 28 & Call Levels & call-levels.com & & $\mathrm{x}$ & & \\
\hline 29 & cashboard & cashboard.de & $\mathrm{x}$ & & & \\
\hline 30 & cashcloud & cashcloud.com & $\mathrm{x}$ & & & \\
\hline 31 & Centralway Numbrs & centralway.com & $\mathrm{x}$ & & & \\
\hline 32 & Circle & circle.com & & $\mathrm{x}$ & & \\
\hline 33 & Circleup & circleup.com & & & $\mathrm{x}$ & $\mathrm{x}$ \\
\hline 34 & Coinbase & coinbase.com & & & & $\mathrm{x}$ \\
\hline 35 & CoinJar & coinjar.com & & $\mathrm{x}$ & & \\
\hline 36 & colleqt & colleqt.com & $\mathrm{x}$ & & & \\
\hline 37 & communitylife & communitylife.de & $\mathrm{x}$ & & & \\
\hline 38 & companisto & companisto.com & $\mathrm{x}$ & & & \\
\hline 39 & Coverfox Insurance & coverfox.com & & $\mathrm{x}$ & & $\mathrm{x}$ \\
\hline 40 & Credit Karma & creditkarma.com & & $\mathrm{x}$ & $\mathrm{x}$ & $\mathrm{x}$ \\
\hline 41 & CreditMantri & creditmantri.com & & $\mathrm{x}$ & & \\
\hline 42 & Cringle & cringle.net & $\mathrm{x}$ & & & \\
\hline 43 & crowdhouse & crowdhouse.ch & & $\mathrm{x}$ & & \\
\hline 44 & cybits & cybits.de & $\mathrm{x}$ & & & \\
\hline 45 & damantis & damantis.com & $\mathrm{x}$ & & & \\
\hline 46 & dban & mydban.de & $\mathrm{x}$ & & & \\
\hline 47 & Digit & digit.co & & & $\mathrm{x}$ & \\
\hline 48 & Doctor Wealth & drwealth.com & & $\mathrm{x}$ & & \\
\hline 49 & Earnest & earnest.com & & & $\mathrm{x}$ & \\
\hline 50 & easyfolio & easyfolio.de & $\mathrm{x}$ & & & \\
\hline 51 & elefunds & elefunds.de & $\mathrm{x}$ & & & \\
\hline 52 & elopay & elopay.com & $\mathrm{x}$ & & & \\
\hline 53 & Equitise & equitise.com & & & & $\mathrm{x}$ \\
\hline 54 & EstateGuru & estateguru.eu & & $\mathrm{x}$ & & \\
\hline 55 & Estimize & estimize.com & & & $\mathrm{x}$ & $\mathrm{x}$ \\
\hline
\end{tabular}


Table 6 (continued)

\begin{tabular}{|c|c|c|c|c|c|c|}
\hline \multirow[t]{2}{*}{ ID } & \multicolumn{2}{|l|}{ FinTech start-up } & \multicolumn{4}{|l|}{ Source } \\
\hline & Name & Website & Bajorat (2015) & CrunchBase (2016) & Sharf (2015) & Toby and Pollari (2015) \\
\hline 56 & eToro & etoro.com & & $\mathrm{x}$ & & $\mathrm{x}$ \\
\hline 57 & fairr & fairr.de & $\mathrm{x}$ & & & \\
\hline 58 & feelix & myfeelix.de & $\mathrm{x}$ & & & \\
\hline 59 & Fentury & fentury.com & & $\mathrm{x}$ & & \\
\hline 60 & Ferratum & ferratumgroup.com & $\mathrm{x}$ & & & \\
\hline 61 & Fidor Bank & fidor.de & & & & $\mathrm{x}$ \\
\hline 62 & FinanceFox & financefox.de & & $\mathrm{x}$ & & \\
\hline 63 & Financelt & financeit.io & & & & $\mathrm{x}$ \\
\hline 64 & finanzcheck & finanzcheck.de & $\mathrm{x}$ & & & \\
\hline 65 & finanzen.de & finanzen.de & $\mathrm{x}$ & & & \\
\hline 66 & Finmar & finmar.com & $\mathrm{x}$ & & & \\
\hline 67 & flatex & flatex.de & & $\mathrm{x}$ & & \\
\hline 68 & FormFree & formfree.com & & $\mathrm{x}$ & & \\
\hline 69 & Friendsurance & friendsurance.de & $\mathrm{x}$ & & & $\mathrm{x}$ \\
\hline 70 & Funding Circle & fundingcircle.com & & & & $\mathrm{x}$ \\
\hline 71 & Fundrise & fundrise.com & & $\mathrm{x}$ & $\mathrm{x}$ & \\
\hline 72 & getsafe & getsafe.de & $\mathrm{x}$ & & & \\
\hline 73 & ginmon & ginmon.de & $\mathrm{x}$ & & & \\
\hline 74 & go4q & go4q.mobi & $\mathrm{x}$ & & & \\
\hline 75 & goHenry & gohenry.co.uk & & & & $\mathrm{x}$ \\
\hline 76 & Goji & goji.com & & $\mathrm{x}$ & & \\
\hline 77 & greenXmoney & greenxmoney.de & $\mathrm{x}$ & & & \\
\hline 78 & helping cents & helpingcents.info & $\mathrm{x}$ & & & \\
\hline 79 & HiFX & hifx.co.uk & & $\mathrm{x}$ & & \\
\hline 80 & HITbills & hitbills.com & & $\mathrm{x}$ & & \\
\hline 81 & HolyTransaction & holytransaction.com & & $\mathrm{x}$ & & \\
\hline 82 & IDnow & idnow.de & $\mathrm{x}$ & & & \\
\hline 83 & idvos & identitiy.tm & $\mathrm{x}$ & & & \\
\hline 84 & Income \& & incomeand.com & & $\mathrm{x}$ & & \\
\hline 85 & Innovative Student Loan Solutions & isloansolutions.com & & $\mathrm{x}$ & & \\
\hline 86 & Instavest & goinstavest.com & & $\mathrm{x}$ & & \\
\hline 87 & Investing.com & investing.com & & $\mathrm{x}$ & & \\
\hline 88 & iPayst & ipayst.com & $\mathrm{x}$ & & & \\
\hline 89 & itBit & itbit.com & & $\mathrm{x}$ & & \\
\hline 90 & Itemize Corp. & itemize.com & & $\mathrm{x}$ & & \\
\hline 91 & iZettle & izettle.com & & & & $\mathrm{x}$ \\
\hline 92 & justETF & justetf.com & $\mathrm{x}$ & & & \\
\hline 93 & Justspent & justspent.com & $\mathrm{x}$ & & & \\
\hline 94 & Kapitall & kapitall.com & & $\mathrm{x}$ & & \\
\hline 95 & Kard & getkard.com & & $\mathrm{x}$ & & \\
\hline 96 & Kesh & kesh.de & $\mathrm{x}$ & & & \\
\hline 97 & kittysplit & kittysplit.com & $\mathrm{x}$ & & & \\
\hline 98 & Klarna & klarna.com & & & & $\mathrm{x}$ \\
\hline 99 & klimpr & klimpr.com & $\mathrm{x}$ & & & \\
\hline 100 & Klinche & klinche.com & & $\mathrm{x}$ & & \\
\hline 101 & Knip & knip.ch & $\mathrm{x}$ & $\mathrm{x}$ & & $\mathrm{x}$ \\
\hline 102 & Kontoalarm & kontoalarm.de & $\mathrm{x}$ & & & \\
\hline 103 & Kontopilot & (AppStore only) & $\mathrm{x}$ & & & \\
\hline 104 & Laterpay & laterpay.net & $\mathrm{x}$ & & & \\
\hline 105 & LearnVest & learnvest.com & & & $\mathrm{x}$ & $\mathrm{x}$ \\
\hline 106 & lendico & lendico.de & $\mathrm{x}$ & & & \\
\hline 107 & Lending Club & lendingclub.com & & $\mathrm{x}$ & & $\mathrm{x}$ \\
\hline 108 & LendInvest & lendinvest.com & & $\mathrm{x}$ & & \\
\hline 109 & LendKey Technologies & lendkey.com & & $\mathrm{x}$ & & \\
\hline 110 & Lendstar & lendstar.io & $\mathrm{x}$ & & & \\
\hline 111 & Level Money & levelmoney.com & & $\mathrm{x}$ & $\mathrm{x}$ & \\
\hline 112 & liveident & liveident.com & $\mathrm{x}$ & & & \\
\hline 113 & Loanbase & loanbase.com & & $\mathrm{x}$ & & \\
\hline 114 & $\mathrm{~m} 8$ & (AppStore only) & $\mathrm{x}$ & & & \\
\hline 115 & mamooble & mamooble.com & $\mathrm{x}$ & & & \\
\hline 116 & minnits & minnits.de & $\mathrm{x}$ & & & \\
\hline 117 & MK Payment Solutions & mkpayment.com & & $\mathrm{x}$ & & \\
\hline 118 & ModernLend & modernlend.com & & $\mathrm{x}$ & & \\
\hline
\end{tabular}


Table 6 (continued)

\begin{tabular}{|c|c|c|c|c|c|c|}
\hline \multirow[t]{2}{*}{ ID } & \multicolumn{2}{|l|}{ FinTech start-up } & \multicolumn{4}{|l|}{ Source } \\
\hline & Name & Website & Bajorat (2015) & CrunchBase (2016) & Sharf (2015) & Toby and Pollari (2015) \\
\hline 119 & Money.net & money.net & & & $\mathrm{x}$ & \\
\hline 120 & moneygarden & moneygarden.de & $\mathrm{x}$ & & & \\
\hline 121 & Moneymeets & moneymeets.com & $\mathrm{x}$ & & & \\
\hline 122 & Motif Investing & motifinvesting.com & & & $\mathrm{x}$ & $\mathrm{x}$ \\
\hline 123 & myiban & myiban.de & $\mathrm{x}$ & & & \\
\hline 124 & MyMicroInvest & mymicroinvest.com & & & & $\mathrm{x}$ \\
\hline 125 & N26 & n26.com & $\mathrm{x}$ & $\mathrm{x}$ & & $\mathrm{x}$ \\
\hline 126 & Nelnet & nelnet.com & & $\mathrm{x}$ & & \\
\hline 127 & Neyber & neyber.co.uk & & $\mathrm{x}$ & & \\
\hline 128 & Nutmeg & nutmeg.com & & & & $\mathrm{x}$ \\
\hline 129 & onlineversicherung.de & onlineversicherung.de & $\mathrm{x}$ & & & \\
\hline 130 & opentabs & opentabs.de & $\mathrm{x}$ & & & \\
\hline 131 & OptionsHouse & optionshouse.com & & $\mathrm{x}$ & & \\
\hline 132 & organize.me & organize.me & $\mathrm{x}$ & & & \\
\hline 133 & Oscar & hioscar.com & & & & $\mathrm{x}$ \\
\hline 134 & Osper & osper.com & & $\mathrm{x}$ & & $\mathrm{x}$ \\
\hline 135 & owlhub. & owlhub.co & $\mathrm{x}$ & & & \\
\hline 136 & paij & paij.com & $\mathrm{x}$ & & & \\
\hline 137 & passt24 & passt24.de & $\mathrm{x}$ & & & \\
\hline 138 & Patientco & patientco.com & & $\mathrm{x}$ & & \\
\hline 139 & paycash & paycash.eu & $\mathrm{x}$ & & & \\
\hline 140 & payfriendz & payfriendz.com & $\mathrm{x}$ & & & \\
\hline 141 & paylax & paylax.de & $\mathrm{x}$ & & & \\
\hline 142 & Payoff & payoff.com & & $\mathrm{x}$ & & \\
\hline 143 & payorshare & payorshare.de & $\mathrm{x}$ & & & \\
\hline 144 & PayRange & payrange.com & & & & $\mathrm{x}$ \\
\hline 145 & paywithatweet & paywithatweet.com & $\mathrm{x}$ & & & \\
\hline 146 & payza & payza.com & $\mathrm{x}$ & & & \\
\hline 147 & Personal Capital & personalcapital.com & & $\mathrm{x}$ & $\mathrm{x}$ & $\mathrm{x}$ \\
\hline 148 & Piggipo & piggipo.com & & $\mathrm{x}$ & & \\
\hline 149 & PolicyBazaar & policybazaar.com & & $\mathrm{x}$ & & $\mathrm{x}$ \\
\hline 150 & Pom & letspom.be & & $\mathrm{x}$ & & \\
\hline 151 & prepaidbitcoin.ph & prepaidbitcoin.ph & & $\mathrm{x}$ & & \\
\hline 152 & PrimaHealth Credit & primahealthcredit.com & & $\mathrm{x}$ & & \\
\hline 153 & Propel & joinpropel.com & & $\mathrm{x}$ & & \\
\hline 154 & Property Partner & propertypartner.co & & & & $\mathrm{x}$ \\
\hline 155 & Prosper & prosper.com & & $\mathrm{x}$ & $\mathrm{x}$ & $\mathrm{x}$ \\
\hline 156 & qnips & qnips.com & $\mathrm{x}$ & & & \\
\hline 157 & Qontis & qontis.ch & $\mathrm{x}$ & & & \\
\hline 158 & qooqo & qooqo.com & $\mathrm{x}$ & & & \\
\hline 159 & quandoo & quandoo.de & $\mathrm{x}$ & & & \\
\hline 160 & Quirion & quirion.de & $\mathrm{x}$ & & & \\
\hline 161 & Qvivr & swypcard.com & & $\mathrm{x}$ & & \\
\hline 162 & RateElert & rateelert.com & & $\mathrm{x}$ & & \\
\hline 163 & ratepay & ratepay.com & $\mathrm{x}$ & & & \\
\hline 164 & Razorpay & razorpay.com & & $\mathrm{x}$ & & \\
\hline 165 & rebit & rebit.ph & & $\mathrm{x}$ & & \\
\hline 166 & Remitly & remitly.com & & $\mathrm{x}$ & & \\
\hline 167 & Rent My Items & rentmyitems.com & & $\mathrm{x}$ & & \\
\hline 168 & Revolut & revolut.com & & & & $\mathrm{x}$ \\
\hline 169 & Robinhood & robinhood.com & & & $\mathrm{x}$ & $\mathrm{x}$ \\
\hline 170 & RupeeTimes & rupeetimes.com & & $\mathrm{x}$ & & \\
\hline 171 & SatoshiPay & satoshipay.io & $\mathrm{x}$ & & & \\
\hline 172 & Savedo & savedo.de & $\mathrm{x}$ & $\mathrm{x}$ & & \\
\hline 173 & schutzklick & schutzklick.de & $\mathrm{x}$ & & & \\
\hline 174 & seedmatch & seedmatch.de & $\mathrm{x}$ & & & \\
\hline 175 & Self Lender & selflender.com & & $\mathrm{x}$ & & \\
\hline 176 & ShapeShift & shapeshift.io & & $\mathrm{x}$ & & \\
\hline 177 & sharewise & sharewise.com & $\mathrm{x}$ & & & \\
\hline 178 & Simple & simple.com & & & $\mathrm{x}$ & \\
\hline 179 & Simply Wall St & simplywall.st & & & & $\mathrm{x}$ \\
\hline 180 & smartdepot & smartdepot.de & $\mathrm{x}$ & & & \\
\hline 181 & smava & smava.de & $\mathrm{x}$ & & & \\
\hline
\end{tabular}


Table 6 (continued)

\begin{tabular}{|c|c|c|c|c|c|c|}
\hline \multirow[t]{2}{*}{ ID } & \multicolumn{2}{|l|}{ FinTech start-up } & \multicolumn{4}{|l|}{ Source } \\
\hline & Name & Website & Bajorat (2015) & CrunchBase (2016) & Sharf (2015) & Toby and Pollari (2015) \\
\hline 182 & SocietyOne & societyone.com.au & & $\mathrm{x}$ & & $\mathrm{x}$ \\
\hline 183 & Sofi & sofi.com & & & $\mathrm{x}$ & \\
\hline 184 & Splittable & splittable.co & & $\mathrm{x}$ & & \\
\hline 185 & SprinkleBit & sprinklebit.com & & $\mathrm{x}$ & & \\
\hline 186 & Squirrel & squirrel.me & & $\mathrm{x}$ & & \\
\hline 187 & sqwallet & sqwallet.de & $\mathrm{x}$ & & & \\
\hline 188 & Stockpile & stockpile.com & & & & $\mathrm{x}$ \\
\hline 189 & Stockspot & stockspot.com.au & & & & $\mathrm{x}$ \\
\hline 190 & StockTouch & stocktouch.com & & $\mathrm{x}$ & & \\
\hline 191 & Swanest & swanest.com & & $\mathrm{x}$ & & \\
\hline 192 & tabbt & tabbt.com & $\mathrm{x}$ & & & \\
\hline 193 & tipranks & tipranks.com & $\mathrm{x}$ & & & \\
\hline 194 & Traity & traity.com & & & & $\mathrm{x}$ \\
\hline 195 & TransferWise & transferwise.com & & $\mathrm{x}$ & $\mathrm{x}$ & $\mathrm{x}$ \\
\hline 196 & treefin & treefin.com & $\mathrm{x}$ & & & \\
\hline 197 & truewealth & truewealth.ch & $\mathrm{x}$ & & & \\
\hline 198 & Tullius Walden & tullius-walden.com & $\mathrm{x}$ & & & \\
\hline 199 & Twindepot & twindepot.de & $\mathrm{x}$ & & & \\
\hline 200 & twingle & twingle.de & $\mathrm{x}$ & & & \\
\hline 201 & United Signals & united-signals.com & $\mathrm{x}$ & & & \\
\hline 202 & vaamo & vaamo.de & $\mathrm{x}$ & & & \\
\hline 203 & Vaamo Finanz AG & blog.vaamo.de & & $\mathrm{x}$ & & \\
\hline 204 & Valuation App & valuationapp.info & & $\mathrm{x}$ & & \\
\hline 205 & vaulted & vaulted.com & $\mathrm{x}$ & & & \\
\hline 206 & Vertragium & vertragium.de & $\mathrm{x}$ & & & \\
\hline 207 & vexcash & vexcash.com & $\mathrm{x}$ & & & \\
\hline 208 & vitrade & vitrade.de & & $\mathrm{x}$ & & \\
\hline 209 & voola & voola.de & $\mathrm{x}$ & & & \\
\hline 210 & Vouch & vouch.com & & & $\mathrm{x}$ & \\
\hline 211 & Wealthfront & wealthfront.com & & $\mathrm{x}$ & $\mathrm{x}$ & $\mathrm{x}$ \\
\hline 212 & webid & webid-solutions.de & $\mathrm{x}$ & & & \\
\hline 213 & WeLend & welend.hk & & $\mathrm{x}$ & & \\
\hline 214 & weltsparen & weltsparen.de & $\mathrm{x}$ & & & \\
\hline 215 & wikifolio.com & wikifolio.com & $\mathrm{x}$ & & & \\
\hline 216 & WiseBanyan & wisebanyan.com & & $\mathrm{x}$ & & \\
\hline 217 & Worldremit & worldremit.com & & & $\mathrm{x}$ & \\
\hline 218 & Харо & xapo.com & & & $\mathrm{x}$ & \\
\hline 219 & xpresscredit & xpresscredit.de & $\mathrm{x}$ & & & \\
\hline 220 & Yacuna & yacuna.com & $\mathrm{x}$ & & & \\
\hline 221 & yapital & yapital.com & $\mathrm{x}$ & & & \\
\hline 222 & Yoyo Wallet & yoyowallet.com & & & & $\mathrm{x}$ \\
\hline 223 & ZahlZ.app & zahlz.com & $\mathrm{x}$ & & & \\
\hline 224 & Zencap & zencap.de & $\mathrm{x}$ & & & \\
\hline 225 & Zinsland & zinsland.de & $\mathrm{x}$ & & & \\
\hline 226 & zinspilot & zinspilot.de & $\mathrm{x}$ & & & \\
\hline 227 & Zopa & zopa.com & & $\mathrm{x}$ & & \\
\hline
\end{tabular}




\section{Measures to decide on cluster solution}

Table 7 Suggested number of clusters of 227 real-life examples of FinTech start-up service offerings (without split into the interaction, data, and monetization perspectives)

\begin{tabular}{ll}
\hline Measure suggested by & $\begin{array}{l}\text { Suggested number } \\
\text { of clusters }\end{array}$ \\
\hline Ball and Hall (1965) & 3 \\
Caliński and Harabasz (1974) & 3 \\
Davies and Bouldin (1979) & 14 \\
Dunn (1974) & 8 \\
Frey and Van Groenewoud (1972) & 1 \\
Halkidi et al. (2000) & 11 \\
Hartigan (1975) & 3 \\
Hubert and Levin (1976) & 14 \\
Krzanowski and Lai (1988) & 14 \\
McClain and Rao (1975) & 2 \\
Milligan (1980, 1981) & 8 \\
Rousseeuw (1987) & 12 \\
Tibshirani et al. (2001) & 2 \\
\hline
\end{tabular}

Open Access This article is distributed under the terms of the Creative Commons Attribution 4.0 International License (http:// creativecommons.org/licenses/by/4.0/), which permits unrestricted use, distribution, and reproduction in any medium, provided you give appropriate credit to the original author(s) and the source, provide a link to the Creative Commons license, and indicate if changes were made.

\section{References}

Agresti, A. (2007). An introduction to categorical data analysis (2nd ed.). New York: Wiley.

Allen \& Overy LLP. (2015). Fintech. Retrieved 1 October 2016. From http://www.allenovery.com/SiteCollectionDocuments/Fintech.PDF

Alt, R., \& Puschmann, T. (2012). The rise of customer-oriented banking electronic markets are paving the way for change in the financial industry. Electronic Markets, 22(4), 203-215.

Alt, R., \& Zimmermann, H. D. (2014). Editorial 24/3: Electronic markets and general research. Electronic Markets, 24(3), 161-164.

Armstrong, J. S. (2002). Principles of Forecasting: A Handbook for Researchers and Practitioners. New York, Boston, Dordrecht, London, Moscow: Kluwer Academic Publishers.

Baars, H., \& Kemper, H.-G. (2008). Management support with structured and unstructured data - an integrated business intelligence framework. Information Systems Management, 25(2), 132-148.

Bacher, J., Pöge, A., \& Wenzig, K. (2010). Clusteranalyse: Anwendungsorientierte Einführung in Klassifikationsverfahre (3rd ed.). Munich: Oldenbourg Wissenschaftsverlag.

Backhaus, K., Erichson, B., Plinke, W., \& Weiber, R. (2011). Multivariate Analysemethoden: Eine anwendungsorientierte Einführung (13th ed.). Berlin/Heidelberg: Springer.
Baden-Fuller, C., \& Haefliger, S. (2013). Business models and technological innovation. Long Range Planning, 46(6), 419-426.

Baesens, B., Bapna, R., Marsden, J. R., Vanthienen, J., \& Zhao, J. L. (2016). Transformational issues of big data and analytics in networked business. MIS Quarterly, 40(4), 807-818.

Bajorat, A. M. (2015). German FinTech Overview. Retrieved 17 May 2015. from http://paymentandbanking.com/2013/11/19/ deutsche-fin-tech-startups-mindmap/

Ball, G. H., \& Hall, D. J. (1965). ISODATA: A novel method of data analysis and pattern classification. Menlo Park: Stanford Research Institute.

BBVA. (2015). Innovation and technology: the digital transformation. Retrieved 14 September 2016. from https://accionistaseinversores. bbva.com/TLBB/micros/bbvain2015/en/performance-in-2015/ bbva-group/innovation-and-technology-the-digital-transformation/

Berkovich, M., Leimeister, J. M., \& Krcmar, H. (2009). Suitability of product development methods for hybrid products as bundles of classic products, software and service elements. In AMSE 2009 - International Design Engingeering Technical Conference \& Computers and Information in Engineering Conference IDETC/CIE. San Diego, USA.

Bharadwaj, A., El Sawy, O. A., Pavlou, P. A., \& Venkatraman, N. (2013). Digital business strategy: Toward a next generation of insights. MIS Quarterly, 37(2), 471-482.

Bose, R. (2009). Advanced analytics: opportunities and challenges. Industrial Management \& Data Systems, 109(2), 155-172.

Bryman, A. (2006). Integrating quantitative and qualitative research: How is it done? Qualitative Research, 6(1), 97-113.

Caliński, T., \& Harabasz, J. (1974). A dendrite method for cluster analysis. Communications in Statistics, 3(1), 1-27.

Chircu, A. M., \& Kauffman, R. J. (1999). Strategies for internet middlemen in the intermediation/disintermediation/Reintermediation cycle. Electronic Markets, 9(1/2), 109-117.

Chuen, D. L. K., \& Teo, E. G. S. (2015). Emergence of FinTech and the LASIC principles. The Journal of Financial Perspectives, 3(3), 1-26. 
Clemons, E. K. (2009). Business models for monetizing internet applications and web sites: Experience, theory, and predictions. Journal of Management Information Systems, 26(2), 15-41.

Cook, D. P., Goh, C.-H., \& Chung, C. H. (1999). Service typologies: A state of the art survey. Production and Operations Management, 8(3), 318-338.

Cormack, R. M. (1971). A review of classification. Journal of the Royal Statistical Society, 134(3), 321-367.

CrunchBase. (2016). CrunchBase. Retrieved 19 April 2016. from https:// about.crunchbase.com/

Dany, O., Goyal, R., Schwarz, J., van den Berg, P., Scortecci, A., \& to Baben, S. (2016). Fintechs may be corporate banks' best "Frenemies." Retrieved 6 September 2016. from https://www.bcgperspectives.com/ content/articles/financial-institutions-technology-digital-fintechs-maybe-corporate-banks-best-frenemies/

Dapp, T. F. (2014). Fintech - The digital (r)evolution in the financial sector. Retrieved 9 September 2016. from https://www.dbresearch.com/ PROD/DBR INTERNET DE-PROD/PROD0000000000345837/ Fintech+ + The +digital+\% $28 \mathrm{r} \% 29$ evolution+in+the+financia.pdf

Dapp, T. F. (2015). Fintech reloaded - Traditional banks as digital ecosystems. Retrieved 9 September 2016. from http://www.dbresearch.com/ PROD/DBR_INTERNET_DE-PROD/PROD0000000000356835/ Fintech+reloaded+ + Traditional+banks+as+digital+ec.PDF

Davies, D. L., \& Bouldin, D. W. (1979). A cluster separation measure. IEEE Transactions on Pattern Analysis and Machine Intelligence, 1(2), 224-227.

Deutsche Bank. (2015). Deutsche Bank announces next phase of strategy. Retrieved 19 June 2016. from https://www.deutsche-bank.de/ medien/en/downloads/Strategie2020_engl 27.04.2015.pdf

Dietz, M., Olanrewaju, T., Khanna, S., \& Rajgopal, K. (2015). Cutting through the noise around financial technology. Retrieved 8 July 2016. from http://www.mckinsey.com/industries/financial-services/ourinsights/cutting-through-the-noise-around-financial-technology

Drummer, D., Jerenz, A., Siebelt, P., \& Thaten, M. (2016). FinTech Challenges and Opportunities - How digitization is transforming the financial sector. Retrieved 6 July 2016 from https://www.mckinsey. de/files/160525_fintech_english.pdf

Dunn, J. (1974). Well separated clusters and optimal fuzzy partitions. Journal of Cybernetics, 4(1), 95-104.

Eisenmann, T., Parker, G., \& Van Alstyne, M. W. (2006). Strategies for two-sided markets. Harvard Business Review, 84, 1-11.

Ferreira, L., \& Hitchcock, D. B. (2009). A comparison of hierarchical methods for clustering functional data. Communications in Statistics - Simulation and Computation, 38(9), 1925-1949.

Field, A. (2013). Discovering Statistics Using IBM SPSS Statistics (4th ed.). Los Angeles, London, New Delhi, Singapore, Washington D.C.: SAGE Publications.

Finch, H. (2005). Comparison of distance measures in cluster analysis with dichotomous data. Journal of Data Science, 3(1), 85-100.

Fishburn, P. C., \& Odlyzko, A. M. (1999). Competitive pricing of information goods: Subscription pricing versus pay-per-use. Economic Theory, 13(2), 447-470.

Fitzsimmons, J. A., \& Fitzsimmons, M. J. (2008). Service management: Operations, strategy, information technology (6th ed.). Boston: McGraw-Hill/Irwin.

Fleiss, J. L. (1971). Measuring nominal scale agreement among many raters. Psychological Bulletin, 76(5), 378-382.

Fraley, C., \& Raftery, A. E. (2002). Model-based clustering, discriminant analysis, and density estimation. Journal of the American Statistical Association, 97(458), 611-631.

Frey, T., \& Van Groenewoud, H. (1972). A cluster analysis of the D-squared matrix of white spruce stands in Saskatchewan based on the maximumminimum principle. Journal of Ecology, 60(3), 873-886.

Froehle, C. M., \& Roth, A. V. (2004). New measurement scales for evaluating perceptions of the technology-mediated customer service experience. Journal of Operations Management, 22(1), 1-21.
Google. (2016). Google trend for fintech. Retrieved 8 September 2016. from https:/www.google.com/trends/explore?date=all\&q=fintech

Gregor, S. (2006). The nature of theory in information systems. MIS Quarterly, 30(3), 611-642.

Guile, B. R., \& Quinn, J. B. (1988). Technology in Services: Policies for growth, trade, and employment. Washington D.C.: National Acadmies Press.

Gulamhuseinwala, I., Bull, T., \& Lewis, S. (2015). FinTech is gaining traction and young, high-income users are the early adopters. The Journal of Financial Perspectives, 3(3), 1-17.

Hair, J. F., Black, W. C., Babin, B. J., \& Anderson, R. E. (2010). Multivariate data analysis. Prentice hall (7th ed.). New Jersey: Pearson Prentice Hall.

Halkidi, M., Vazirgiannis, M., \& Batistakis, I. (2000). Quality Scheme Assessment in the Clustering Process. In Proceedings of the 4th PKDD Conference (pp. 265-276). Lyon, France.

Hands, S., \& Everitt, B. (1987). A Monte Carlo study of the recovery of cluster structure in binary data by hierarchical clustering techniques. Multivariate Behavioral Research, 22(2), 235-243.

Hartigan, J. A. (1975). Clustering algorithms. New York: Wiley.

Hochstein, M. (2015). Fintech (the Word, That Is) Evolves. Retrieved 15 July 2016. from www.americanbanker.com/bankthink/fintech-theword-that-is-evolves-1077098-1.html

Hope, A. C. A. (1968). A simplified Monte Carlo significance test procedure. Journal of the Royal Statistical Society. Series B (Methodological), 30(3), 582-598.

Hubert, L. J., \& Levin, J. R. (1976). A general statistical framework for assessing categorical clustering in free recall. Psychological Bulletin, 83(6), 1072-1080.

Iansiti, M., \& Levien, R. (2004). The keystone advantage: What the new dynamics of business ecosystems mean for strategy, innovation, and sustainability. Boston: Harvard Business School Press.

Janssen, M., Charalabidis, Y., \& Zuiderwijk, A. (2012). Benefits, adoption barriers and myths of open data and open government. Information Systems Management, 29(4), 258-268.

Kashyap, M., Garfinkel, H., Shipman, J., Davies, S., \& Nicolacakis, D. (2016). Blurred lines: How FinTech is shaping Financial Services. Retrieved 28 September 2016. from http://www.pwc.de/de/ finanzdienstleistungen/assets/pwc-fintech-global-report.pdf

Kim, Y., Choi, J., Park, Y. J., \& Yeon, J. (2016). The adoption of mobile payment services for "Fintech". International Journal of Applied Engineering Research, 11(2), 1058-1061.

Krzanowski, W. J., \& Lai, Y. T. (1988). A criterion for determining the number of groups in a data set using sum-of-squares clustering. Biometrics, 44(1), 23-34.

Landis, J. R., \& Koch, G. G. (1977). The measurement of observer agreement for categorical data. Biometrics, 33(1), 159-174.

Leimeister, J. M. (2012). Dienstleistungsengineering und-management. Berlin, Heidelberg: Springer Verlag.

Lesser, E. L., \& Fontaine, M. A. (2004). Learning from the connected customer: Enhancing customer web sites with community. In Creating value with knowledge: Insights from the IBM Institute for business value (pp. 134-140). New York, Oxford: Oxford University Press.

Linoff, G. S., \& Berry, M. J. (2002). Mining the web: Transforming customer data into customer value. New York: Wiley.

Lusch, R. F., \& Nambisan, S. (2013). Service innovation: A servicedominant (S-D) logic perspective. MIS Quarterly, 39(1), 155-175.

Ma, D. (2015). Push or pull? A Website's strategic choice of content delivery mechanism. Journal of Management Information Systems, 32(1), 291-321.

Mackenzie, A. (2015). The Fintech revolution. London Business School Review, 3, 50-53.

McClain, J. O., \& Rao, V. R. (1975). CLUSTISZ: A program to test for the quality of clustering of a set of objects. Journal of Marketing Research, 12(4), 456-460. 
Mead, W., Pollari, I., Fortnum, D., Hughes, B., \& Speier, A. (2016). The Pulse of Fintech. Retrieved 4 September 2016. from https://assets. kpmg.com/content/dam/kpmg/pdf/2016/03/the-pulse-of-fintech.pdf

Meffert, H., \& Bruhn, M. (2009). Dienstleistungsmarketing (6th ed.). Wiesbaden: Gabler.

Milligan, G. W. (1980). An examination of the effect of six types of error perturbation on fifteen clustering algorithms. Psychometrika, 45(3), $325-342$.

Milligan, G. W. (1981). A Monte Carlo study of thirty internal criterion measures for cluster analysis. Psychometrika, 46(2), 187-199.

Milligan, G. W., \& Cooper, M. C. (1985). An examination of procedures for determining the number of clusters in a data set. Psychometrika, 50(2), 159-179.

Milligan, G. W., \& Cooper, M. C. (1988). A study of standardization of variables in cluster analysis. Journal of Classification, 5(2), 181-204.

Moore, J. (1996). The death of competition: Leadership \& strategy in the age of business ecosystems. New York: HarperCollins.

Nickerson, R. C., Varshney, U., \& Muntermann, J. (2013). A method for taxonomy development and its application in information systems. European Journal of Information Systems, 22(3), 336-359.

O'Sullivan, J., Edmond, D., \& Ter Hofstede, A. (2002). What's in a service? Towards accurate description of non-functional service properties. Distributed and Parallel Databases, 12, 117-133.

Oxford English Dictionary. (n.d.). Definition of fintech. Retrieved 8 September 2016. from http://www.oxforddictionaries.com/de/ definition/englisch/fintech

Park, Y., Geum, Y., \& Lee, H. (2012). Toward integration of products and services: Taxonomy and typology. Journal of Engineering and Technology Management, 29(4), 528-545.

Postmus, D., Wijngaard, J., \& Wortmann, H. (2009). An economic model to compare the profitability of pay-per-use and fixed-fee licensing. Information and Software Technology, 51(3), 581-588.

Rao, C. R. (1948). The utilization of multiple measurements in problems of biological classification. Journal of the Royal Statistical Society. Series B (Methodological), 10(2), 159-203.

Rousseeuw, P. (1987). Silhouettes: A graphical aid to the interpretation and validation of cluster analysis. Journal of Computational and Applied Mathematics, 20, 53-65.

Rysman, M. (2009). The economies of two-sided markets. Journal of Economic Perspectives, 23(3), 125-143.

Saraçli, S., Dogan, N., \& Dogan, I. (2013). Comparison of hierarchical cluster analysis methods by cophenetic correlation. Journal of Inequalities and Applications, 203(1), 1-8.

Setia, P., Venkatesh, V., \& Joglekar, S. (2013). Leveraging digital technologies: How information quality leads to localized capabilities and customer service performance. MIS Quarterly, 37(2), 565-590.
Sharf, S. (2015). The Fintech 50: The Complete List. Retrieved 20 January 2016. from http://www.forbes.com/sites/samanthasharf/ 2015/12/09/the-fintech-50-the-complete-list

Skilton, M. (2015). Building the digital Enterprise: A guide to constructing monetization models using digital technologies. Basingstoke: Palgrave Macmillon.

Sneath, P. H. A. (1957). Some thoughts on bacterial classification. Journal of General Microbiology, 17(1), 184-200.

Sneath, P. H., \& Sokal, R. R. (1973). Numerical taxonomy: The principles and practice of numerical classification: A series of books in biology. San Francisco: Freeman.

Sokal, R. R., \& Michener, C. D. (1958). A statistical method for evaluating systematic relationships. University of Kansas Bulletin, 38(2), $1409-1438$.

Sousa, R., \& Voss, C. A. (2006). Service quality in multichannel services employing virtual channels. Journal of Service Research, 8(4), 356-371.

The Economist Intelligence Unit. (2015). The disruption of banking. Retrieved 25 May 2016. from https://www.eiuperspectives.economist. $\mathrm{com} /$ sites/default/files/EIU-The disruption of banking_PDF_0.pdf.

Tibshirani, R., Walther, G., \& Hastie, T. (2001). Estimating the number of clusters in a data set via the gap statistic. Journal of the Royal Statistical Society B, 63(2), 411-423.

Toby, H., \& Pollari, I. (2015). Fintech 100. Retrieved 25 January 2016. from http://fintechinnovators.com/uploads/H2-Fintech-Innovators-2015.pdf

Vargo, S. L., \& Lusch, R. F. (2004). Evolving to a new dominant logic for marketing. Journal of Marketing, 68(1), 1-17.

Walker, L. (1998). Amazon Gets Personal With E-Commerce. Retrieved 10 August 2016. from http://www.washingtonpost.com/wp-srv/ washtech/daily/nov98/amazon110898.htm

Ward, J. H. (1963). Hierarchical grouping to optimize an objective function. Journal of the American Statistical Association, 58(301), 236-244.

Weglarz, G. (2004). Two worlds of data unstructured and structured. DM Review, 14(9), 19-22.

Wells, N., \& Wolfers, J. (2000). Finance with a personalized touch. Communications of the ACM, 43(8), 31-34.

Wu, J. (2012). Advances in K-means clustering. Berlin, Heidelberg: Springer.

Xu, H., Teo, H.-H., Tan, B. C. Y., \& Agarwal, R. (2010). The role of pushpull Technology in Privacy Calculus: The case of location-based services. Journal of Management Information Systems, 26(3), 135-174.

Zavolokina, L., Dolata, M., \& Schwabe, G. (2016). FinTech - What's in a name? In Proceedings of the International Conference on Information Systems (pp. 1-19). Dublin, Ireland.

Zhang, D., Chen, M., \& Zhou, L. (2005). Dynamic and personalized web services composition in E-business. Information Systems Management, 22(3), 50-65. 